ARQUEOLOGÍA DE LA ARQUITECTURA, 17, enero-diciembre 2020, e095

Madrid / Vitoria

ISSN-L: $1695-2731$

https://doi.org/10.3989/arq.arqt.2020.004

\title{
Evaluación de los Sistemas de Mapeo Móvil (MMS) en la documentación gráfica del tholo de El Romeral (Conjunto Arqueológico Dólmenes de Antequera)
}

\section{Mobile Mapping Systems (MMS) performance evaluation to generate the graphic documentation of the tholo of "El Romeral" (Antequera archaeologic dolmens site)}

\author{
José Antonio Benavides López ${ }^{1}$ \\ Universidad de Granada \\ José Antonio Barrera Vera² \\ Universidad de Sevilla
}

\section{RESUMEN}

Este artículo hace un análisis comparado de los nuevos sistemas de mapeo móvil (MMS) basados en la tecnología SLAM (Simultaneous Localization and Mapping) respecto de sistemas de registro gráfico ya consolidados como el escaneado TLS (Terrestrial Laser Scanner), la fotogrametría multi-imagen SFM (Structure from Motion), aportando novedades de carácter metodológico y utilizando como elemento de análisis el tholo de El Romeral, singular construcción prehistórica perteneciente al conjunto dolménico de Antequera. El experimento ha servido para analizar factores tan importantes como precisión geométrica, tiempos de captura y procesamiento, viabilidad económica o calidad de la documentación gráfica obtenida. La facilidad y rapidez que a portan las tecnologías de mapeo móvil simultáneo permiten una mejor y más completa documentación gráfica del patrimonio arquitectónico y arqueológico, incluso en aquellos lugares que se consideran inviables para el resto de tecnologías. La evaluación del dispositivo MMS sobre el tholo de El Romeral nos ha aportado una precisión geométrica similar a los otros sistemas de captura, pero la falta de textura de estas nubes de puntos impide el análisis paramental de las estructuras.

Palabras clave: SLAM; documentación gráfica; fotogrametría; TLS; SFM; construcciones funerarias; construcciones megalíticas; Málaga.

\begin{abstract}
This article carries out a comparative analysis of the cutting-edge technology SLAM (Simultaneous Location and Mapping) implemented in mobile mapping systems (MMS). It compares this technology with others well-known recording systems, such as Terrestrial Laser Scanning (TLS) and Structure From Motion (SFM) photogrammetry, and it shows as well its methodological development applied to the tholo of "El Romeral", an unique prehistoric construction belonging to the Antequera Dolmen Archaeological Site. This research has helped thus to analyse important factors such as geometric accuracy, capturing and processing times, economic viability or quality of the resulting graphic documentation. Being quick and easy, simultaneous mobile mapping technologies make it possible to obtaining better and more complete graphic records of architectural and archaeological heritage, even in those sites considered unfeasible for other technologies. Testing MMS systems on the tholo of "El Romeral" has provided us with a geometric precision similar to the others capture systems. However, the lack of texture of these clouds of points does not allow to analyse standing structures.
\end{abstract}

Key words: SLAM; graphic documentation; photogrammetry; TLS; SFM; funeral constructions; megalithic constructions; Malaga.

Recibido: 29-10-2019. Aceptado: 17-01-2020. Publicado online: 27-04-2020

Cómo citar este artículo / Citation

Benavides-López, J. A. y Barrera-Vera, J. A. 2020: "Evaluación de los Sistemas de Mapeo Móvil (MMS) en la documentación gráfica del tholo de El Romeral (Conjunto Arqueológico Dólmenes de Antequera)", Arqueología de la Arquitectura, 17: e095. https://doi.org/10.3989/arq.arqt.2020.004

Copyright: (c) CSIC, 2020. (c) UPV/EHU Press, 2020. Este es un artículo de acceso abierto distribuido bajo los términos de la licencia de uso y distribución Creative Commons Reconocimiento 4.0 Internacional (CC BY 4.0).

jbenavid@ugr.es / ORCID iD: https://orcid.org/0000-0002-2321-113X

barrera@us.es / ORCID iD: https://orcid.org/0000-0003-1069-4846 


\section{INTRODUCCIÓN}

La singularidad y la relevancia histórica del tholo de El Romeral hacen que sea un escenario ideal para el desarrollo de esta investigación cuya finalidad es evaluar la tecnología de registro MMS (Mapeo Móvil Simultáneo al desplazamiento) al tiempo que contribuir al conocimiento y valorización del sitio arqueológico, aportando documentos gráficos y datos que pueden ser relevantes para futuras intervenciones o investigaciones.

El tholo o túmulo de El Romeral forma parte del Conjunto Arqueológico Dólmenes de Antequera junto con los dólmenes de Menga y Viera conformando uno de los paisajes arqueológicos más complejos e interesantes de Europa y un importante referente de las primeras construcciones megalíticas ${ }^{3}$.

El tholo de El Romeral es un sepulcro de falsa cúpula formado por un corredor y dos cámaras de planta circular de diferente tamaño y función. Todos sus muros, a excepción de los vanos de acceso, se ejecutaron mediante la técnica de mampostería, diferenciándose de este modo respecto de los dólmenes de Menga y Viera construidos íntegramente mediante megalitos (Ruiz González 2011: 182). El corredor, de 23 m de longitud y $1,90 \mathrm{~m}$ de altura, presenta una sección trapezoidal debido a la inclinación de sus muros $\left(11,20^{\circ}\right.$ respecto de la vertical) (Fig. 1a). En su interior se abren dos cámaras de paredes ligeramente abovedadas y conectadas mediante un pequeño corredor (Fig. 1b). La primera cámara es considerablemente más grande $(5,20 \mathrm{~m}$ de diámetro en la base y $3,72 \mathrm{~m}$ de altura) que la segunda (2,40 $\mathrm{m}$ de diámetro en la base y 2,30 de altura) estando cubiertas, al igual que el corredor, mediante grandes losas de piedra. Posteriormente, esta construcción se cubre con un gran túmulo artificial de tierra y piedras de unos $85 \mathrm{~m}$ de diámetro y unos $6 \mathrm{~m}$ de altura máxima.

Es un hecho constatado la imprescindible necesidad de documentación gráfica del patrimonio arquitectónico o arqueológico como herramienta fundamental para el análisis, comprensión, intervención (Martínez Rubio et al. 2018) y en su caso, para la difusión de sus valores artísticos o culturales (Martín Talaverano 2014), lo que no queda hoy tan claro es qué tecnología de registro es la más eficaz en cada caso y cuáles deben ser los requisitos exigibles a las nuevas representaciones para

\footnotetext{
Plan Director del Conjunto Arqueológico Dólmenes de Antequera. http://www.museosdeandalucia.es/documents/1971642/0/Plan+Director/ 366c2710-e175-4eae-b0b2-a29729a21c4b
}
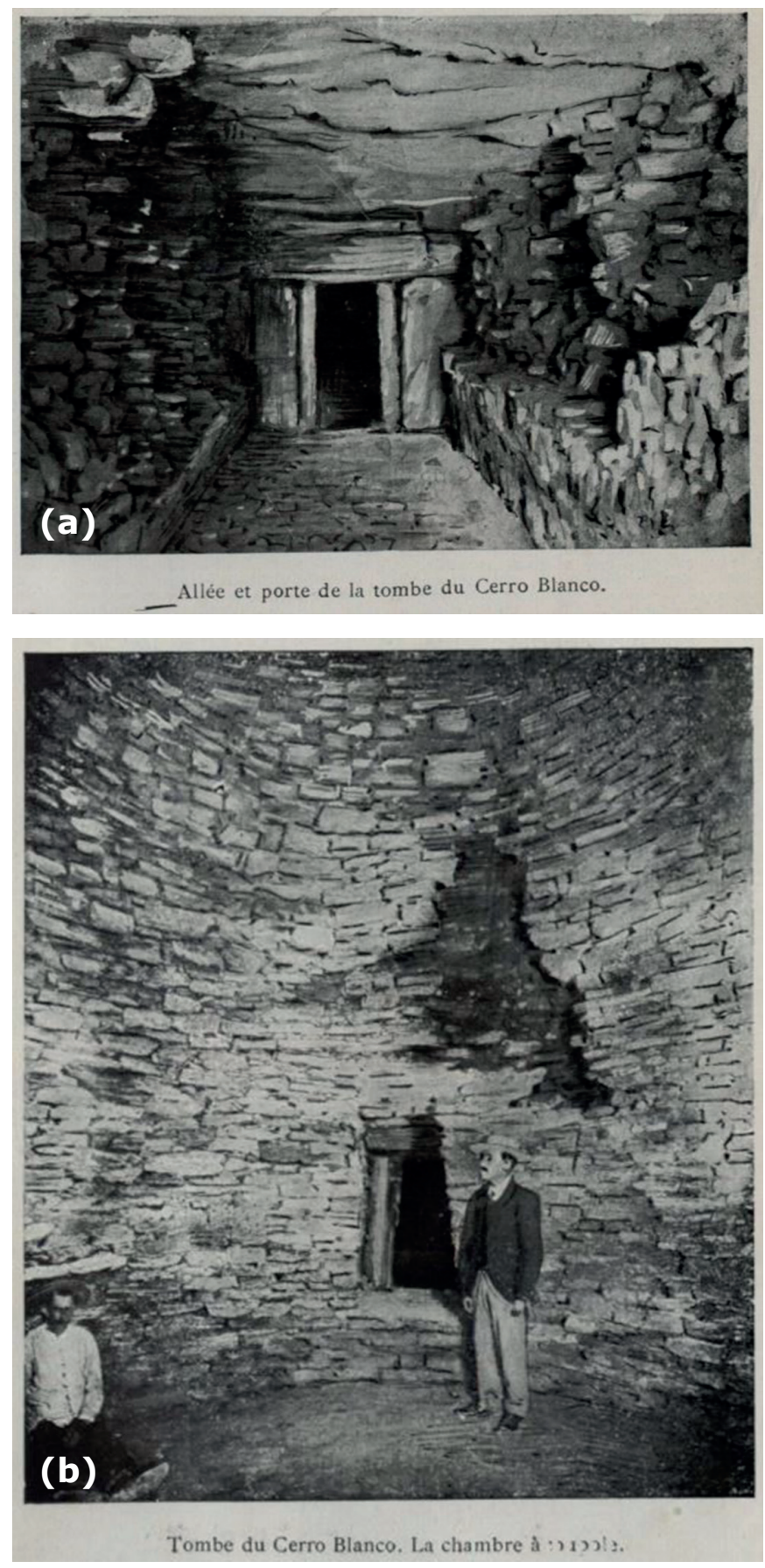

Figura 1. Imagen del corredor (a) e imagen de la primera cámara (b) realizada en el año 1920, que muestran el estado de conservación del tholo de El Romeral, también Ilamado de Cerro Blanco en esa fecha (Paris, P. 1920).

que estas aporten mejores resultados. Factores como la rapidez, precisión, presupuesto, tipo de intervención, capacitación del operador, plazo de entrega disponible o las características específicas del elemento a documentar van a condicionar el tipo de equipos y metodología a desarrollar. 
Sin lugar a dudas, los nuevos sistemas de captura y representación tridimensional mediante nubes de puntos están transformando los paradigmas en los trabajos de documentación del patrimonio construido, haciéndolos mucho más eficientes y precisos, mejorando significativamente su comprensión. En la actualidad son ampliamente conocidas las metodologías de registro llevadas a cabo mediante escáner láser terrestre $\left(\mathrm{TLS}^{4}\right)$ o fotogrametría multi-imagen $\left(\mathrm{SfM}^{5}\right)$ (Barrera 2006; Biosca et al. 2009; Lerma et al. 2011; Rodríguez-Navarro 2012; Gonizzi et al. 2012; Benavides 2017; Chiabrando et al. 2018), así como la utilización de Estaciones Totales para un mejor ajuste y georreferenciación a partir de los puntos de control. Recientemente ha surgido una nueva tecnología denominada dispositivo de Mapeo Móvil Simultáneo (MMS) que mejora la eficacia respecto de los otros sistemas, permitiendo el registro digital continuo y simultáneo al desplazamiento del operador. Estos sistemas constituyen actualmente la forma más eficiente de representación del patrimonio arquitectónico y arqueológico, capturando la complejidad del espacio tridimensional mediante una nube densa de puntos sin apenas oclusiones, pero que también presenta inconvenientes que es necesario describir.

Los sistemas de mapeo móvil (MMS) (Fig. 2) constan de tres componentes principales: a) un sensor LIDAR $^{6}$ para el mapeo 3D/2D (nube de puntos mediante medición láser), b) una unidad para el posicionamiento y navegación espacial formada por una unidad de medición inercial $\left(\mathrm{IMU}^{7}\right)$ y/o un sensor óptico y c) una unidad de referencia de tiempo que funciona como sistema central que sincroniza e integra todos los datos mediante algoritmos SLAM (Simultaneous Localization and Mapping).

La tecnología SLAM surgió en la conferencia IEEE de 1986 gracias a las contribuciones de diferentes investigadores sobre la introducción de métodos probabilísticos aplicados a la robótica y la Inteligencia Artificial (IA) y que se reflejarían años después en trabajos como los de Smith, Self y Cheeseman (1990). La tecnología SLAM ha sido ampliamente estudiada en la industria robótica, aunque debido a las patentes asociadas ha tenido poca difusión.

\footnotetext{
$4 \quad$ TLS (Terrestrial Laser Scanner): escáner láser terrestre, también conocidos como HDS (High-Definition Surveying).

5 SFM (Structure from Motion): estructura desde el movimiento de la cámara. 6 LIDAR (Light Detection and Ranging o Laser Imaging Detection and Ranging): dispositivo que permite determinar la distancia desde un emisor láser a un objeto o superficie utilizando un haz láser pulsado.

7 IMU (Inertial Measurement Unit): unidad de medición inercial, dispositivo electrónico que mide e informa acerca de la velocidad, orientación y fuerzas gravitacionales de un aparato, usando una combinación de acelerómetros y giróscopos.
}

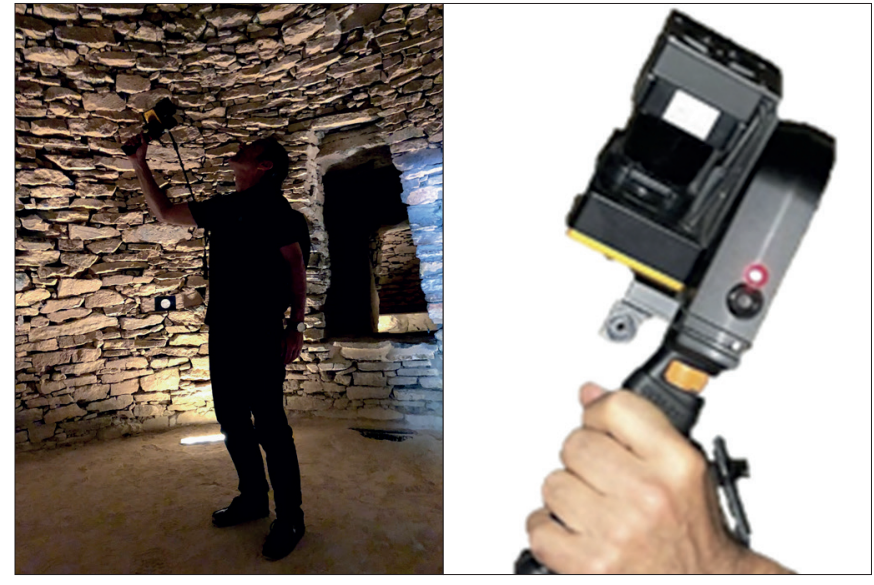

Figura 2. Captura de la geometría del tholo de El Romeral mediante el instrumento MMS GeoSlam ZEB-REVO. ZEB-REVO de GeoSLAM Scanner 3D facilitado por la empresa Geoavance S.L. Sevilla. Elaboración propia.

Actualmente está teniendo un gran desarrollo gracias al uso de plataformas de código abierto y al abaratamiento de los equipos. Entre las plataformas que se utilizan para realizar SLAM podemos destacar Hector-SLAM, plataforma perteneciente a ROS (Robot Operting System) que realiza mapeos a partir de las mediciones realizadas por un sensor LIDAR y la estimación de la posición basada en sensores inerciales (Kohlbrecher et al. 2013). En este sistema, la representación del entorno utiliza un mapa de cuadrícula que combina los datos de los escaneos de las nuevas posiciones con respecto a los resultados anteriormente registrados.

El enfoque es una mezcla inteligente de geometría, teoría de grafos, optimización y probabilística. SLAM tiene como objetivo construir una representación global y coherente del entorno, aprovechando las medidas de su propio movimiento $\mathrm{y}$, fundamentalmente, cerrando el ciclo. Comprobada que la localización basada en el movimiento sobre las ruedas (odometría) era poco precisa, las investigaciones se han centrado en determinar la posición continua mediante el uso de unidades de medición inercial (IMU) y el seguimiento de referencias visuales externas a través de sensores ópticos (Lynen et al. 2015).

Desde hace más de una década, sofisticados sistemas de mapeado móvil montados sobre vehículos (Fig. 3), como (a) Leica Pegasus ${ }^{\circledR}$, (b) el VMX450® de Riegl o (c) IP-S3 de Topcom®, son ampliamente utilizados para el registro y la planificación urbana, obteniendo una información más completa y en mucho menor tiempo que el resto de las técnicas (Fig. 4). Por lo general, todos estos componentes incorporan sistemas de navegación por satélite GNSS ${ }^{8}$,

\footnotetext{
8 GNSS (Global Navigation Satellite System): sistema global de navegación por satélite.
} 

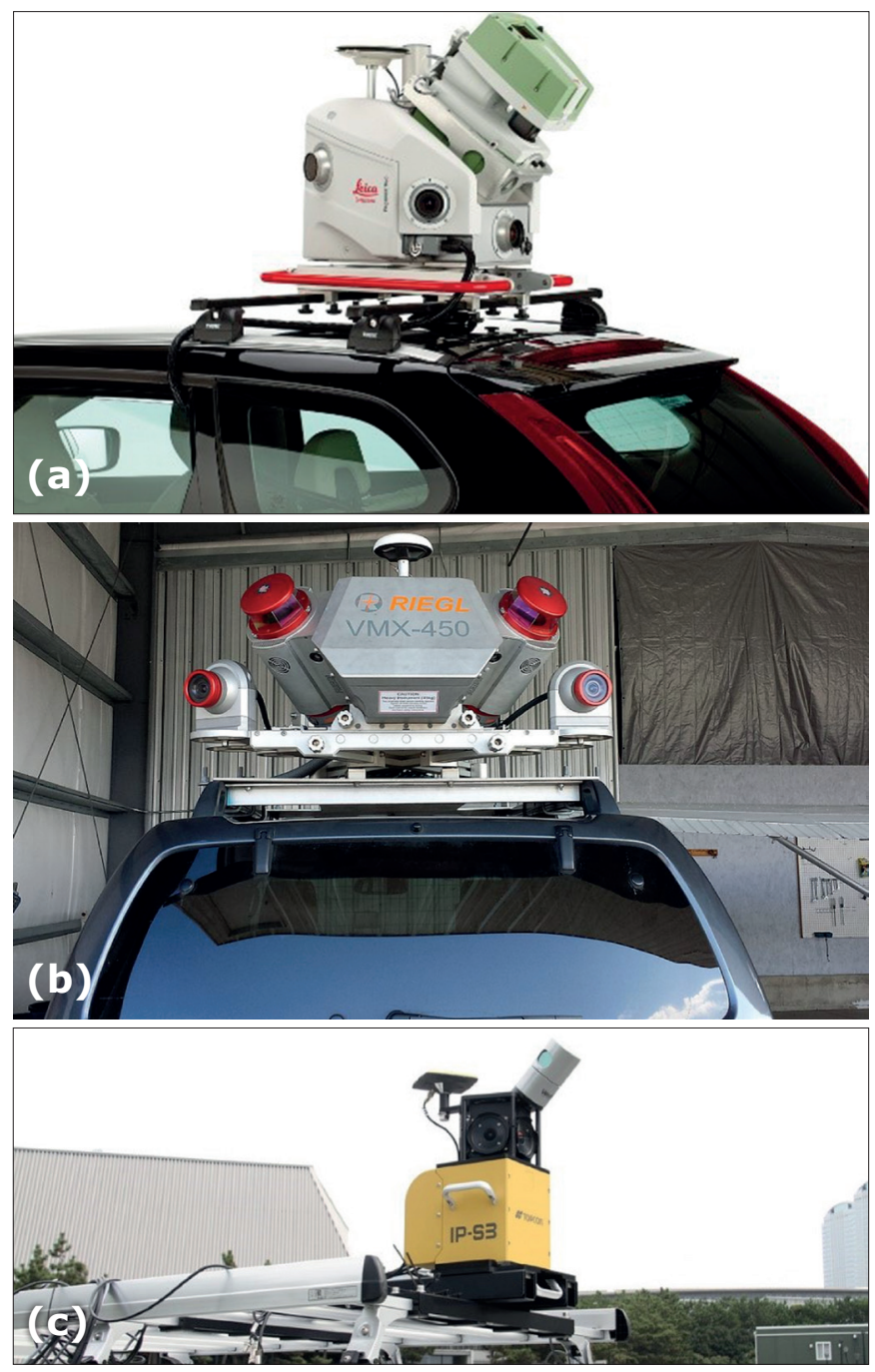

Figura 3. (a) Leica Pegasus $®$ (b) VMX450® de Riegl (c) IP-S3 $®$ de Topcom.

unidades de medición inercial (IMU), medidores Láser y cámaras digitales. En otros casos, como Leica Pegasus, también pueden incorporar cámaras térmicas, sensores de contaminación acústica o incluso georradar (GPR) para la realización de cartografias subterráneas. Sin embargo, la complejidad, tamaño y sobre todo el coste de estos equipos los hace inviables para la mayoría de los escenarios relacionados con la arquitectura o arqueología, estando limitado su uso a espacios exteriores con cobertura satelital.

Los avances tecnológicos han permitido la fabricación de equipos cada vez más pequeños y ligeros de forma que puedan ser transportados manualmente o sobre un dron $\left(\mathrm{UAV}^{9}\right)$. Sistemas comerciales como GeoSlam

\footnotetext{
9 UAV (Unmanned Aerial Vehicle): vehículo aéreo no tripulado o comúnmente dron. También RPA (Remotely Piloted Aircraft), vehículo aéreo remotamente tripulado.
}

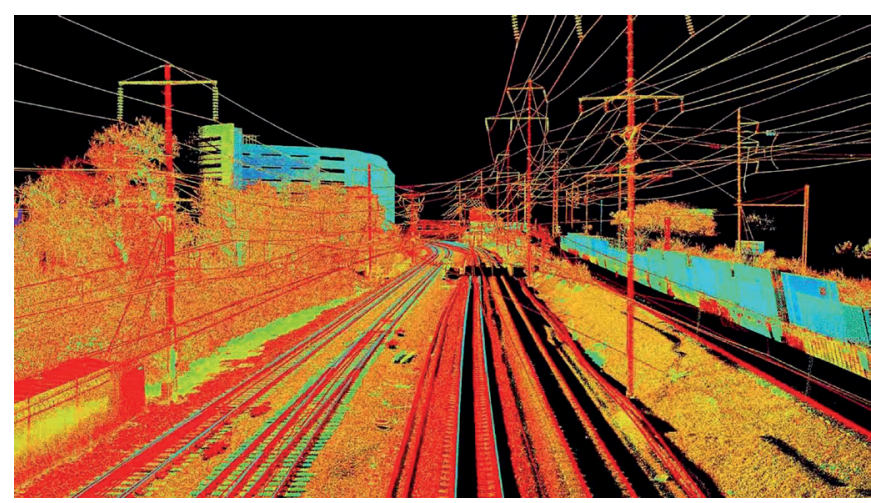

Figura 4. Nube de puntos capturada mediante el sistema Moving mapping leica Pegasus montado sobre vagón. Fuente: web de Leica Geosystems.

Zeb-Revo (utilizado en esta investigación) o el Leica ${ }^{\circledR}$ Pegasus Backpack ${ }^{10}$, u otros no comerciales como los diseñados por Filgueira et al. (2016) o Karam et al. (2019) pueden ser transportados en una mochila utilizando un LiDAR 3D y una IMU para la adquisición de datos tanto en interiores como en exteriores. De igual forma, la importante reducción de los precios ha contribuido a su mayor difusión.

Los sistemas de mapeo móvil (MMS) no tienen la precisión de los escáneres láser situados sobre trípode (TLS), pero capturan los datos de forma más fácil y rápida, con la precisión suficiente para la mayoría de los escenarios relacionados con la arquitectura y el urbanismo, estando especialmente indicados en entornos complejos como instalaciones industriales, edificios antiguos, calles estrechas, cuevas, jardines o galerías subterráneas. Los MMS proporcionan una nube densa con resolución cuasi uniforme que va a depender de la velocidad del desplazamiento y de la distancia al objeto. Otro factor importante es que esta tecnología no necesita del apoyo de puntos de control capturados por topografía ni de los complejos registros y procesamiento de los escaneos realizados con equipos de escáner láser terrestre (TLS).

El dispositivo utilizado en nuestra investigación GeoSLAM Zeb-Revo (Fig. 5) es un sistema de mapeo móvil (MMS) desarrollado por el Laboratorio de Sistemas Autónomos CSIRO ICT de Australia (Bosse et al. 2012) y cuyas especificaciones técnicas aparecen reflejadas en la tabla 1. La versión actualizada cuenta con un cabezal Lidar giratorio (UTM-30LX) ${ }^{11}$ de tiempo de

\footnotetext{
$10 \mathrm{https}$ //leica-geosystems.com/es-es/products/mobile-sensor-platforms/ capture-platforms/leica-pegasus-backpack (consultado el 22/01/2020).

https://www.robotshop.com/media/files/pdf2/utm-30lx-ew_specification. pdf (consultado el 22/01/2020).
} 


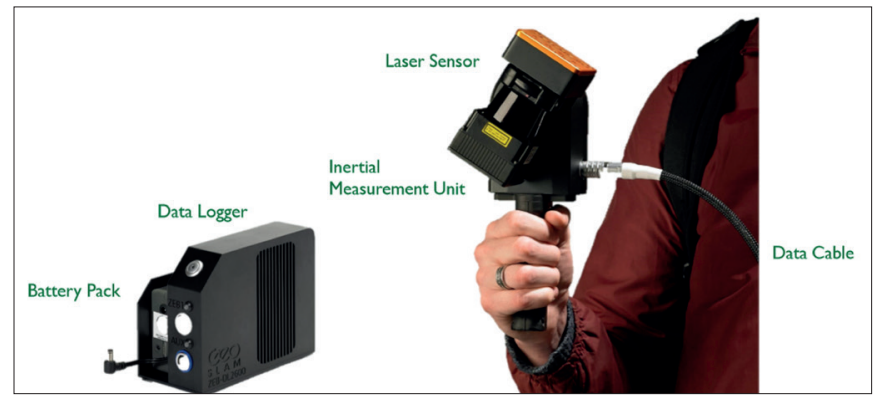

Figura 5. Dispositivo GeoSLAM ZEB-REVO utilizado en la investigación (https://geoslam.com/).

\begin{tabular}{|l|l|}
\hline Velocidad de adquisición datos & 43.200 medidas puntos/segundo \\
\hline Error relativo & +/ $15 \mathrm{~mm}$ \\
\hline $\begin{array}{l}\text { Precisión absoluta de la } \\
\text { posición }\end{array}$ & $\begin{array}{l}\text { Dependiente del entorno } \\
\text { (típicamente } 3-30 \mathrm{~cm}\end{array}$ \\
\hline Alcance máximo & Hasta $30 \mathrm{~m}(15 \mathrm{~m}$ en el exterior) \\
\hline Clase de seguridad láser & Clase 1. Seguridad para el ojo \\
\hline Campo de visión angular & 270 x 360 grados \\
\hline Clasificación IP & $\begin{array}{l}\text { IP64 (a prueba de polvo y } \\
\text { prueba de salpicaduras) }\end{array}$ \\
\hline Velocidad de línea del escáner & $100 \mathrm{~Hz}$ \\
\hline
\end{tabular}

Fuente https://geoslam.com/

Tabla 1. Especificaciones técnicas de Zeb REVO.

\begin{tabular}{|l|l|}
\hline Rango (m) & $\begin{array}{l}0,1-30 \text { nominal } \\
0,1-60 \text { max }\end{array}$ \\
\hline Campo de visión (grados) & 270 \\
\hline Resolución angular (grados) & 0,25 \\
\hline Velocidad de escaneo (Hz) & 40 \\
\hline Precisión de rango (mm) & \pm 50 (a 10m de rango) \\
\hline Longitud de onda (nm) & 905 \\
\hline Voltaje (V) & $10,8-13,2$ (12 nominales) \\
\hline Potencia (W) (nominal / max) & $8 / 12$ \\
\hline Peso (lb / kg) & $0,46 / 0,21$ \\
\hline $\begin{array}{l}\text { Durabilidad (subjetiva: (pobre) } \\
1 \text { - 5 (excelente)) }\end{array}$ & 3 \\
\hline Interfaz de salida & USB 2.0 \\
\hline Costo $€$ & 4500 \\
\hline
\end{tabular}

Tabla 2. Especificaciones técnicas de cabezal lidar utm-30lx.

vuelo $\left(\mathrm{ToF}^{12}\right)$ (Tab. 2), acoplado a un soporte con mango manual que incorpora un sensor inercial (IMU tipo MEMS $^{13}$ ) que consta de giroscopios, magnetómetros y

\footnotetext{
12 ToF (Time-of-Flight): tiempo de vuelo, tiempo que tarda la onda en ir y volver al sensor.

$13 \mathrm{https} / / / \mathrm{www} \cdot$ analog.com/media/en/news-marketing-collateral/solutionsbulletins-brochures/MEMS-IMU-Brochure.pdf (consultado el 22/01/2020).
}

acelerómetros triaxiales y que permiten una localización estimada del sensor a partir de la determinación de las mediciones de velocidades angulares y aceleraciones lineales en combinación con los datos medidos con el escáner láser. Ambos sistemas se conectan por cable a una unidad central $\left(\mathrm{CPU}^{14}\right)$ donde se registran y almacenan los datos y a una batería que aporta energía a todo el sistema. En el año 2017 surge una nueva generación "GeoSLAM ZEB CAM" ${ }^{15}$ que incorpora una cámara digital gran angular que permite, según indica el fabricante, dar textura a la nube de puntos.

La condición indispensable y necesaria de los sistemas SLAM es realzar un ciclo cerrado (Zhang y Singh 2014), es decir, se debe inicializar el equipo desde una superficie horizontal para posteriormente, tras realizar el recorrido de escaneado, volver a la misma posición de partida, consiguiendo de esta forma compensar el error acumulado en el cierre. Finalmente, los datos deben ser descargados y procesados de forma autónoma mediante la aplicación GeoSLAM Hub ${ }^{16}$, ejecutándose en un equipo local o mediante un procesamiento en la nube.

\section{MATERIALES Y MÉTODOS}

De acuerdo con los dos objetivos planteados en nuestro trabajo, completa y exhaustiva documentación gráfica del tholo de El Romeral y evaluación de los nuevos sistemas de registro de mapeo móvil aplicados a la documentación del patrimonio arqueológico, hemos procedido a realizar un estudio comparado de diferentes tecnologías de registro: (1) un levantamiento, considerado como referencia, realizado mediante equipo escáner láser terrestre (Leica C-10); (2) un doble levantamiento fotogramétrico - uno realizado en el interior del tholo mediante cámara réflex Nikon D800 sobre trípode y otro mediante vuelo con dron (DJIPhantom 4 pro) (Fig. 6d) para el exterior-y (3) un doble levantamiento interior mediante equipo MMS GeoSlam Zeb-Revo a diferente velocidad de desplazamiento.

Como paso previo al registro por los diferentes métodos se ha establecido una red de puntos de control. Se han situado 20 puntos en el interior y 10 en el exterior mediante la fijación de dianas adheridas en suelos $\mathrm{y}$ paramentos y que posteriormente han sido medidas

\footnotetext{
14 CPU (Central Processing Unit): unidad central de procesamiento.

15 https://geoslam.com/wp-content/uploads/2018/01/GeoSLAM-HUB-Installation-Guide-V4.0.1.pdf?x97867 (consultada 22/01/2020).

${ }_{16}$ GeoSLAM ${ }^{\circledR}$ 2019. Zeb Revo RT. https://geoslam.com/zeb-revort/ (consultado el 22/01/2020).
} 


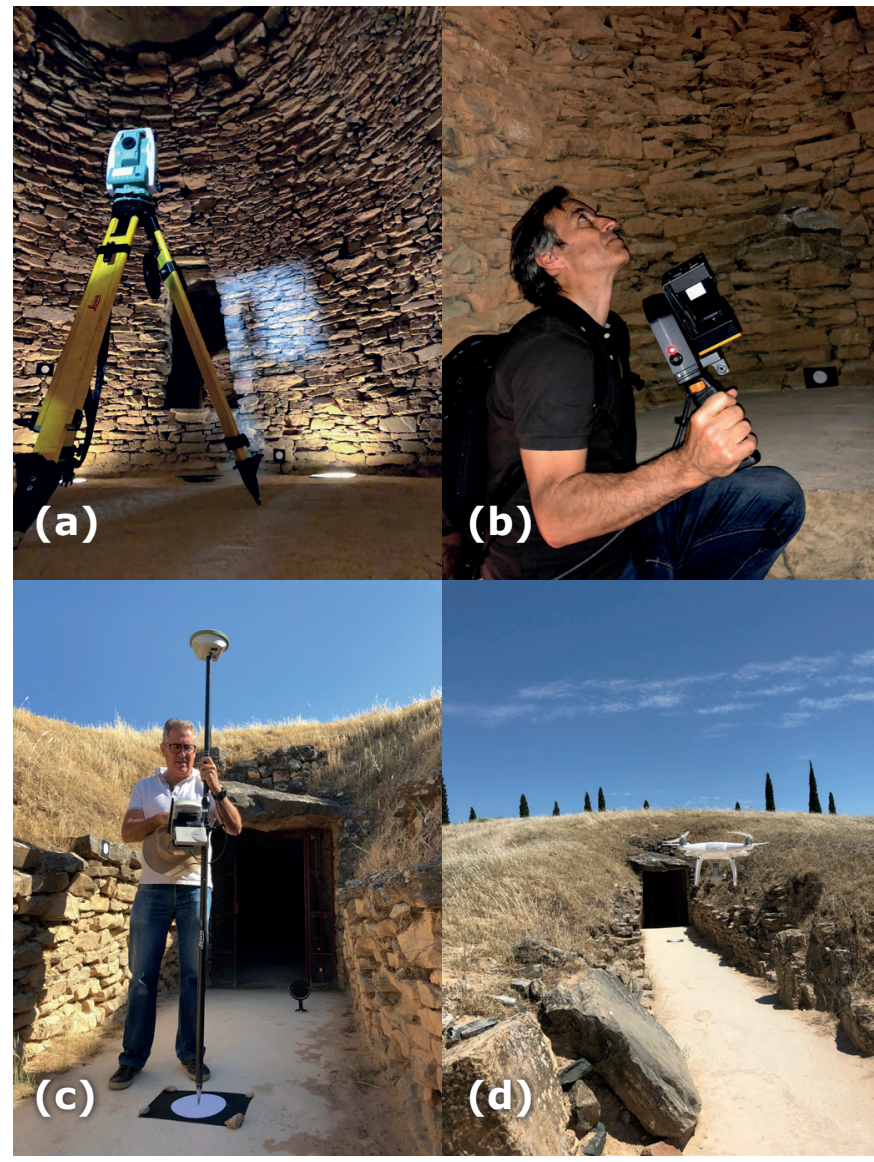

Figura 6. Instrumentos utilizados en la documentación del tholo de El Romeral. (a) Estación Total Leica TS06 para medición puntos de control, (b) Escaner MMS Zeb-Revo, (c) Sistema DGPS-Leica 1200, (d) Drone DJI Phantom 4 pro. Elaboración propia.

mediante Estación Total (Leica TS06) con distanciometría láser. Estos puntos permiten el ajuste y control de calidad de los datos obtenidos (Fig. 6a) logrando precisiones superiores a $3 \mathrm{~mm}$ en la captura de los puntos.

La geolocalización del tholo de El Romeral en el sistema de referencia universal (UTM-ETRS89) se ha realizado sobre los puntos de control exteriores

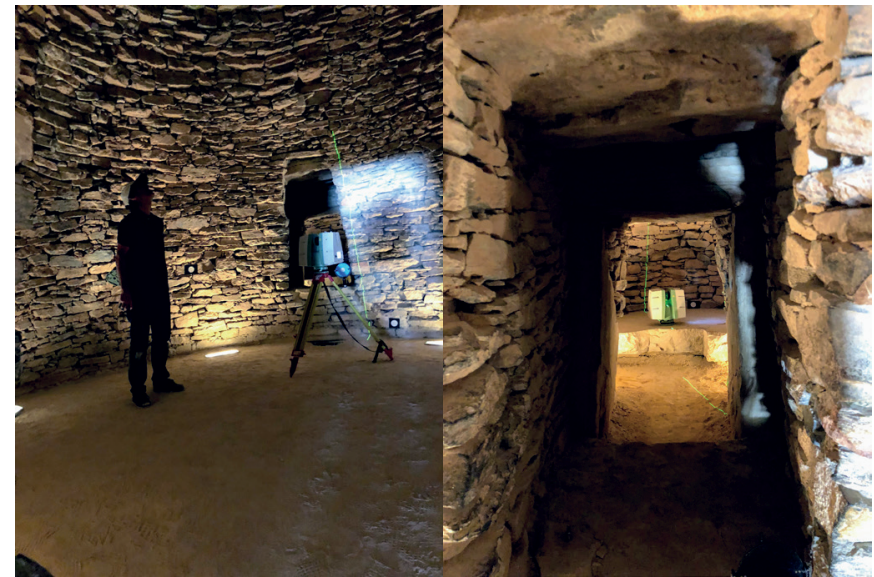

Figura 7. Posicionamiento de equipo TLS Leica C10 en las cámaras funerarias. La pequeña dimensión del pasillo que las comunica obliga a un nuevo estacionamiento intermedio. Elaboración propia.

mediante un equipo de posicionamiento global en tiempo real GNSS-RTK (Leica Smart-Rover 1200) conectado a la Red Nacional de Instituto Geográfico (Fig. 6c). La precisión en el posicionamiento mediante este equipo ha oscilado entre 1 y $2 \mathrm{~cm}$ dependiendo del número y geometría de los satélites en el momento de la captura.

\subsection{Levantamiento con escáner láser terrestre (TLS)}

Como elemento de referencia para el análisis y control de los datos, se ha realizado un levantamiento de alta precisión mediante equipo TLS Leica C10 (Fig. 7) apoyado en los puntos de control topográfico capturados con Estación Total.

Para solucionar la falta de homogeneidad en el registro de la nube de puntos con TLS, consecuencia del paso de giro secuencial de estos equipos, que se ve afectado por la distancia al objeto o de la orientación y geometría de los paramentos (García-Gómez et al.

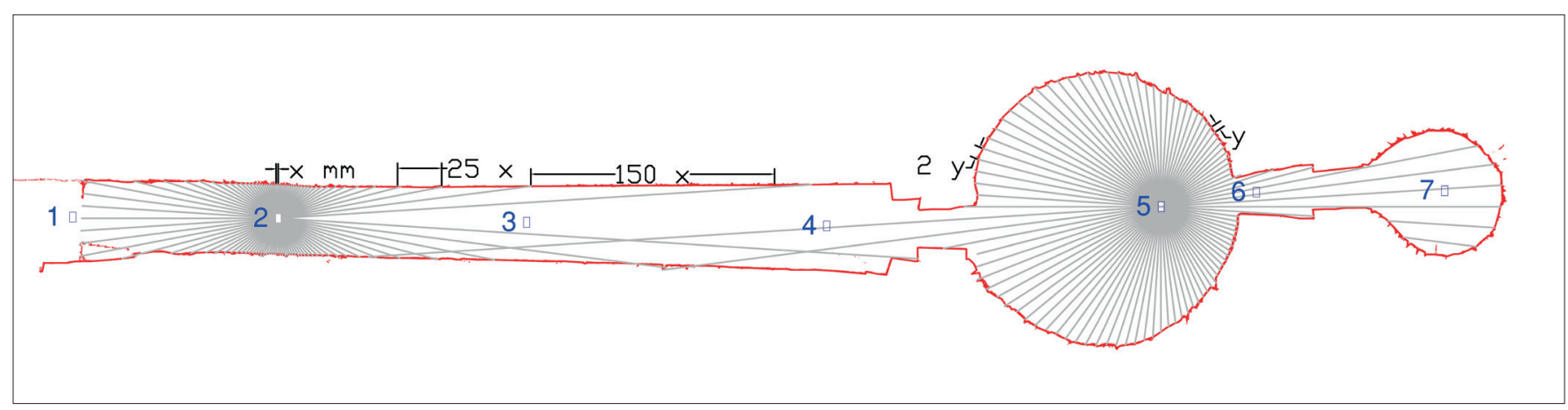

Figura 8. Esquema de la dispersión geométrica por registro TLS y situación de los diferentes posicionamientos del equipo: 4 escaneados en el corredor (posiciones 1, 2, 3 y 4), 1 escaneado en cada una de las cámaras (posición 5 y 7) y 1 escaneado en vano de acceso a segunda cámara (posición 6). 
2011), ha sido necesario un registro sistemático desde diferentes posiciones (Fig. 8). La estrechez y longitud del corredor interior $(1,30 \mathrm{~m} \times 15,70 \mathrm{~m})$ provoca una gran dispersión de los datos (ver posición 2), obligando a realizar 4 escaneados sucesivos (posiciones 1 al 4). Por el contrario, la geometría regular de las cámaras necesita de un solo posicionamiento en cada una de ellas (posición 5 y 7). La estrechez del hueco que comunica las dos cámaras ha obligado a realizar un nuevo escaneo intermedio (posición 6) para el registro del hueco y para interrelacionar los registros de las dos cámaras.

La alineación de las diferentes nubes de puntos en un mismo sistema de referencia se ha realizado mediante los puntos de control y del algoritmo ICP (Iterative Closest Point) (Szeliski 2010), utilizando para ello el software Cyclone de Leica Geosystems ${ }^{17}$ que proporciona un error absoluto medio inferior a $3 \mathrm{~mm}$. El registro de los paramentos desde diferentes posiciones produce una mayor densificación de los puntos en las zonas de solape. Así, las nubes generadas mediante escáner láserterrestre TLS constan de 145 millones de puntos, muy superior al que aportan los otros sistemas de registro.

\subsection{Levantamiento mediante fotogrametría multi-imagen}

Para la realización de la zona interior del tholo por fotogrametría multi-imagen se ha utilizado una cámara digital no calibrada Nikon D800 que cuenta con un sensor Full frame de $36 \mathrm{MgPix}$, recurriendo a un objetivo gran angular Nikkor-14 mm debido a la poca amplitud del corredor. Por otro lado, la escasa iluminación interior del tholo obliga a aumentar el tiempo de exposición en la captura, necesitando la utilización de trípode (Fig. 9a). La estrechez del pasillo y las cámaras interiores necesitó la captura de 172 imágenes. Las tomas han sido procesadas con el software Agisoft Photoscan-profesional ${ }^{18}$ ver-1.4.4, obteniéndose una nube densa de 49 millones de puntos con un GSD de $0.543 \mathrm{~mm} /$ pix (Fig. $9 b)$ y un RMS en la reproyección de $0,9 \mathrm{~mm}$.

La zona exterior del tholo ha sido tomada mediante vuelo fotogramétrico programado a baja altura (24 m) mediante la aplicación Map-Pilot (Fig. 10a), utilizando para ello un equipo UAV DJI Phantom 4 Pro y procesado mediante la aplicación de escritorio Agisoft

\footnotetext{
https://leica-geosystems.com/es-es/products/laser-scanners/software/leica-cyclone (consultado el 22/01/2020).

18 AgiSoft LLC 2018.
}
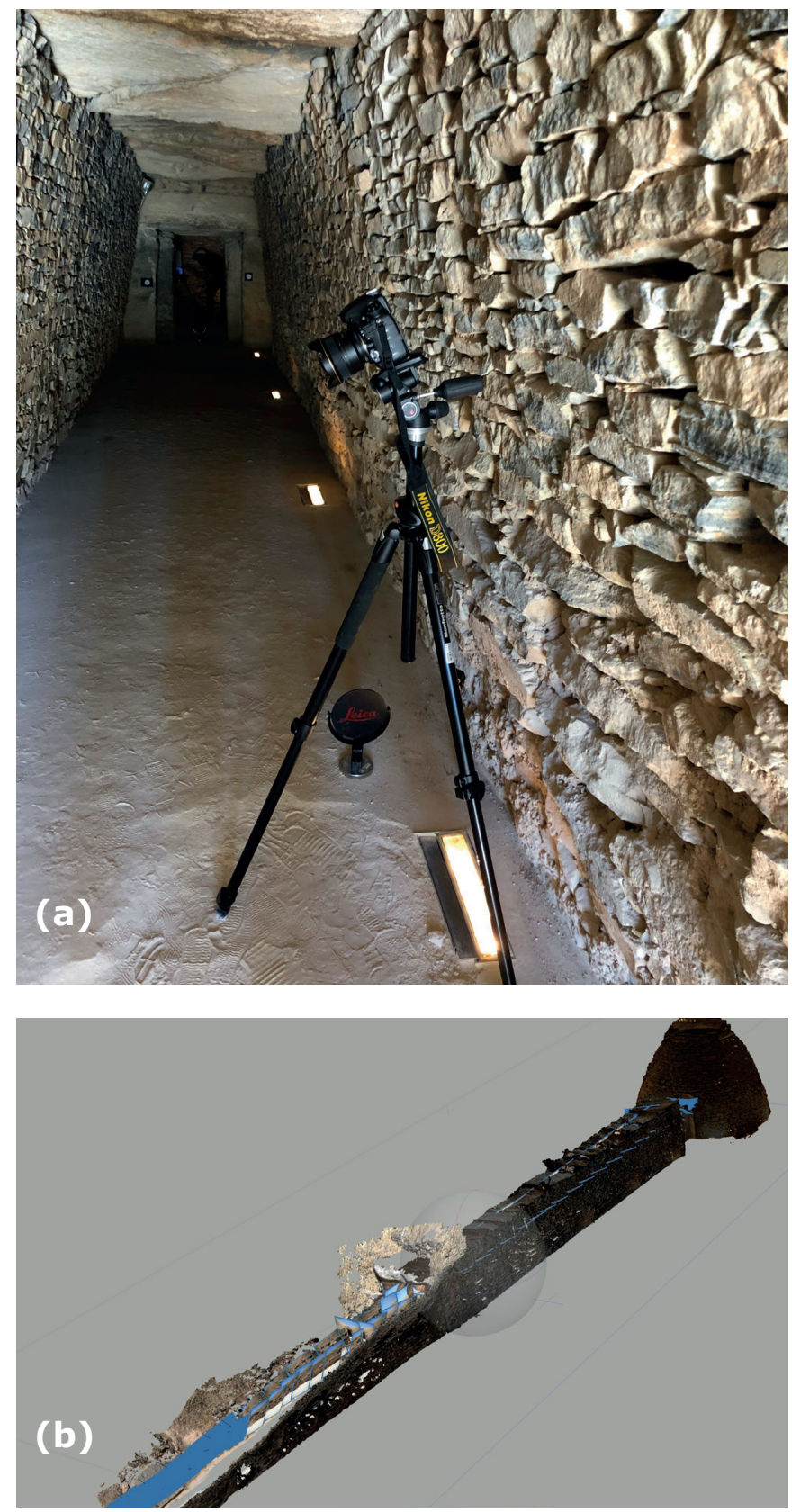

Figura 9. (a) Captura fotográfica del interior del corredor con cámara Nikon D800 y objetivo fijo Nikkor $14 \mathrm{~mm}$. (b) Captura del modelo digital 3D de la nube de puntos densa del interior generada por fotogrametría multi-imagen mediante la aplicación Agisoft Photoscan profesional. Elaboración propia.

Photoscan-profesional (Fig. 10b), obteniéndose una nube densa, con filtro medio, de 41 millones de puntos con un GSD de $8 \mathrm{~mm} /$ pix y un RMS en la reproyección de $12 \mathrm{~mm}$ (1,33 pix).

En ambos casos, ha sido necesaria la captura de puntos de control topográficos (dianas), que permita georreferenciar y fusionar las distintas nubes de puntos adquiridas por escaneo láser y por procesamiento SFM 

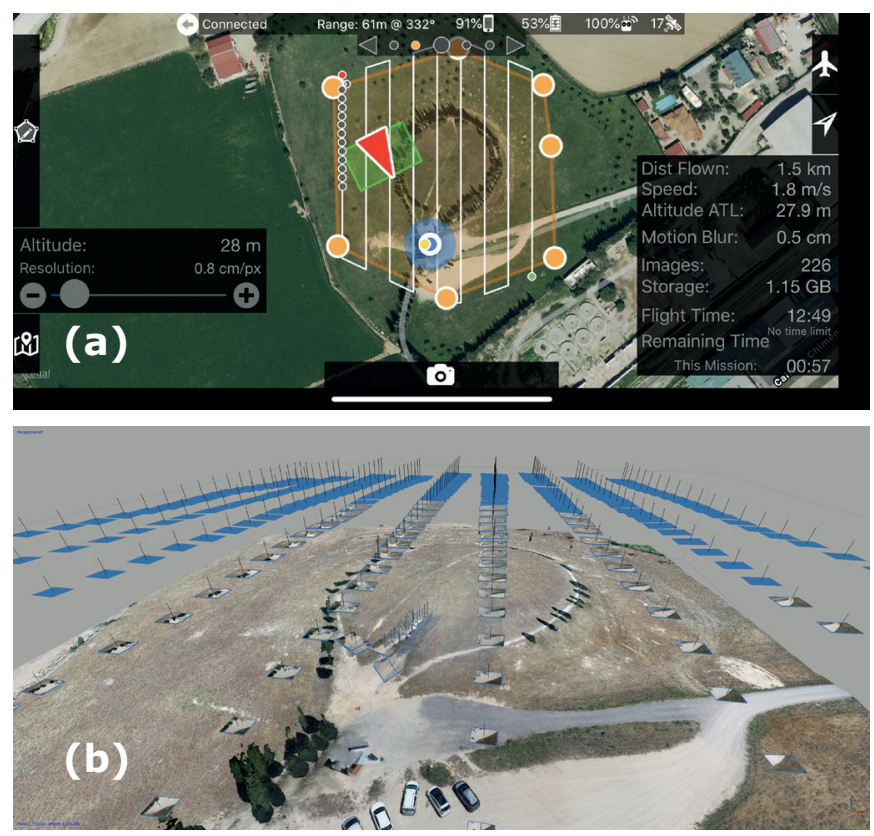

Figura 10. (a) Programación del vuelo mediante la aplicación Map-Pilot. (b) Captura del modelo digital exterior del tholo con la distribución de imágenes orientadas mediante Agisoft photoscan profesional. Elaboración propia.

a partir de imágenes capturadas con UAV y por cámara sobre trípode (Moon et al. 2019). En este sentido, la estrechez del corredor y del pasillo de conexión entre ambas cámaras ha dificultado sobremanera la realización de un itinerario cerrado de ida y vuelta con conexión en los puntos de control exteriores. Si bien la precisión en la medida electrónica de distancias (EDM) mediante láser es de $2 \mathrm{~mm}+2 \mathrm{ppm}$, la estrechez del tholo provoca ángulos de rebote pobres que conducen a una peor precisión (RMS $4 \mathrm{~mm}$ ).

\subsection{Levantamiento mediante dispositivo MMS}

Se ha realizado un doble levantamiento interior a diferente velocidad de desplazamiento mediante el equipo MMS GeoSlam Zeb-Revo. El procedimiento consiste en arrancar el equipo desde una superficie horizontal, sujetando posteriormente por el mango manual para realizar un recorrido andando a una velocidad lenta, dirigiendo el cabezal en la dirección del avance y realizando cuantos giros laterales sean necesarios para la completa captura de la geometría del elemento a documentar. La localización estimada del sensor en todo momento se realiza a partir de las mediciones de velocidades angulares y aceleraciones lineales de los acelerómetros triaxiales, conjuntamente con una referenciación basada en la geometría de la nube de puntos ya medida, por este motivo, cuando se va a entrar en una estancia sin referencias previas es recomendable girarse y entrar de espaldas. Pero, sin lugar a dudas, la condición indispensable y necesaria de la tecnología SLAM es terminar en el mismo punto de partida, cerrando de esta manera el ciclo para que permita compensar los errores acumulados.

La distancia total del ciclo es de $62 \mathrm{~m}$, en un intervalo de tiempo de $15 \mathrm{~min}$, inferior a los $30 \mathrm{~min}$ que establece el fabricante como máximo recomendable en un solo ciclo. El rango de distancia de escaneo, dadas las características del tholo, se ha mantenido siempre por debajo de $1,5 \mathrm{~m}$, muy por debajo del rango máximo recomendado que es $10 \mathrm{~m}$ (aunque el rango máximo en condiciones óptimas es de $30 \mathrm{~m}$ ).

La realización de los dos ciclos se justifica en la necesidad de contrastar, sobre un mismo modelo, los resultados entre ellos. El primer ciclo se realizó a un ritmo de marcha lento para garantizar una buena cobertura y mayor resolución de datos. El recorrido se realizó evitando la presencia de visitantes que pudieran dificultar y distorsionar los resultados. En última instancia se realizó un segundo ciclo a mayor velocidad para poder detectar posibles interferencias y discordancias entre los dos escaneos. Puesto que los resultados obtenidos en ambos fueron congruentes, la nube de puntos empleada para este estudio ha sido la más densa, es decir, la realizada a menor velocidad.

\section{RESULTADOS}

El método adoptado para evaluar el equipo MMS -GeoSlam Zeb-Revo- consiste en tres análisis: evaluación de la calidad geométrica de la nube de puntos respecto a las obtenidas por equipos TLS y por fotogrametría multi-imagen (apartado 3.1); evaluación del rendimiento en cuanto tiempo de captura y procesamiento (apartado 3.2); evaluación de la calidad gráfica de los documentos obtenidos (apartado 3.3).

\subsection{Análisis de la calidad geométrica de la nube de puntos}

La estrategia más común para cuantificar la calidad resultante de las nubes de puntos generadas por los dispositivos MMS consiste en comparar las desviaciones (nube de puntos a nube de puntos) respecto de las generadas 
por equipos TLS utilizando el software CloudCompare ${ }^{19}$ (Sirmacek et al. 2016; Lehtola et al. 2017). En nuestro caso, el análisis de la calidad geométrica se ha realizado comparando las desviaciones de la nube de puntos generada por el dispositivo GeoSLAM ZEB REVO respecto de las nubes de puntos generadas con un escáner láser ToF Leica $C-10$ y por fotogrametría multi-imagen SFM.

La compleja geometría del interior del tholo, formado por un corredor de gran longitud y estrecha sección y por dos cámaras de muy diferente tamaño unidas entre sí por estrechos vanos o huecos con mala comunicación, hace que debamos plantear un análisis geométrico de las diferentes nubes en su conjunto. Es aquí donde el sistema SLAM muestra su fortaleza respecto de otros sistemas al realizar un mapeado 3D continuo y homogéneo del yacimiento independientemente de la

19 CloudCompare 2015, CloudCompare Ver. 2.6.1: Paris, EDF R\&D, Telecom ParisTech [Software]. complejidad geométrica del elemento a documentar. Las investigaciones realizadas por otros autores (Maboudi et al. 2017; Nocerino et al. 2017; Tucci et al. 2018) analizan la menor precisión de los equipos MMS respecto de los datos obtenidos desde una sola posición de escáner mediante equipo TLS en condiciones ideales. Pero, es precisamente en la acumulación de errores por el ajuste y alineación de las distintas nubes de puntos TLS cuando estos equipos pierden precisión en favor de los sistemas MMS (Barrera y Benavides 2018).

Por lo general, la baja resolución y el alto nivel de ruido que proporcionan los equipos MMS dificultan un adecuado análisis cuantitativo de sus desviaciones respecto de otras nubes de puntos. El procedimiento seguido para analizar la bondad del modelo MMS generado por el sistema GeoSlam Zeb Revo respecto de los otros dos sistemas ha consistido en el examen de las desviaciones en diferentes secciones realizadas a lo largo del modelo (Fig. 11).

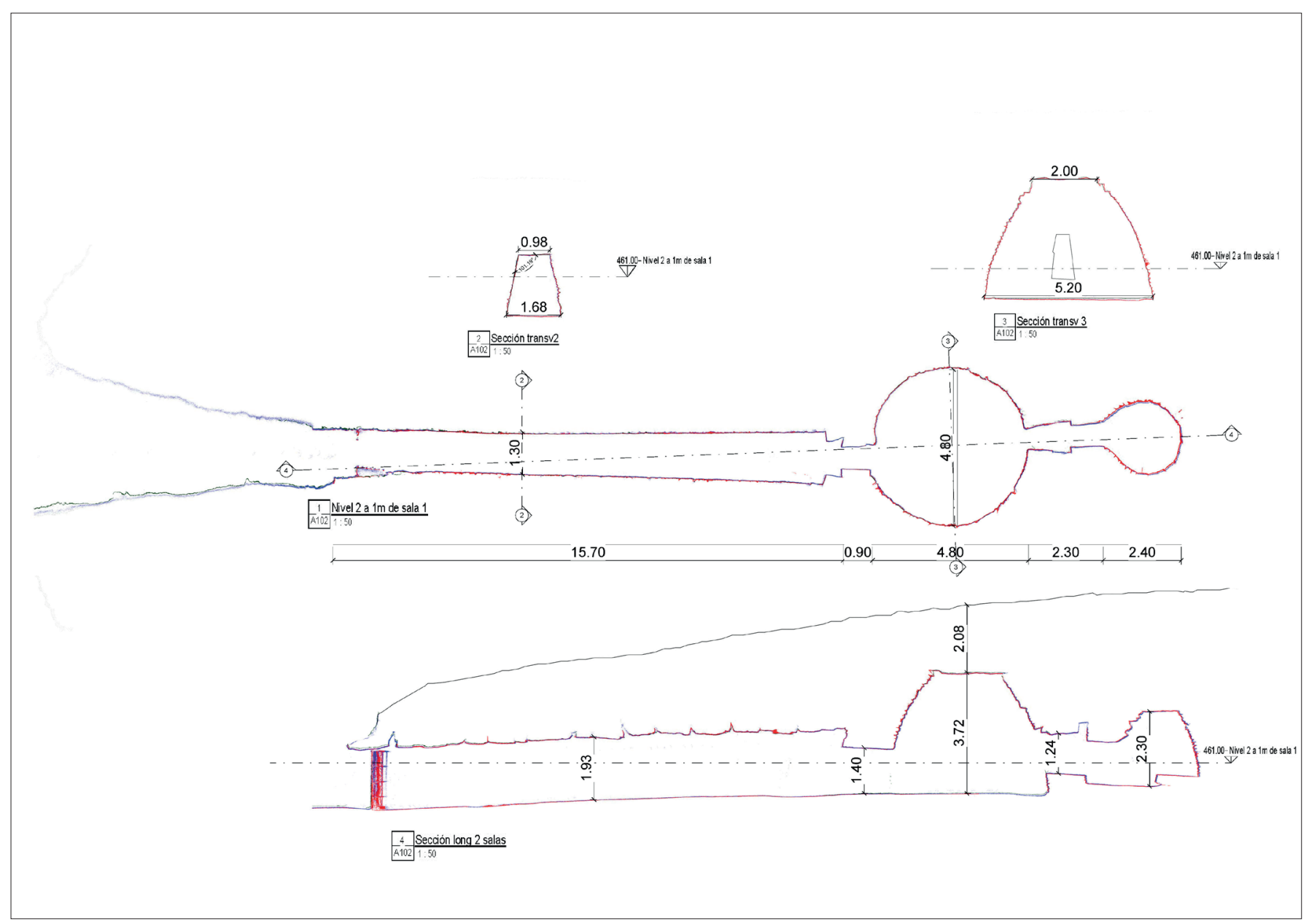

Figura 11. Planos de planta y sección del tholo de El Romeral a partir de la sección de las tres nubes de puntos. Elaboración propia. 

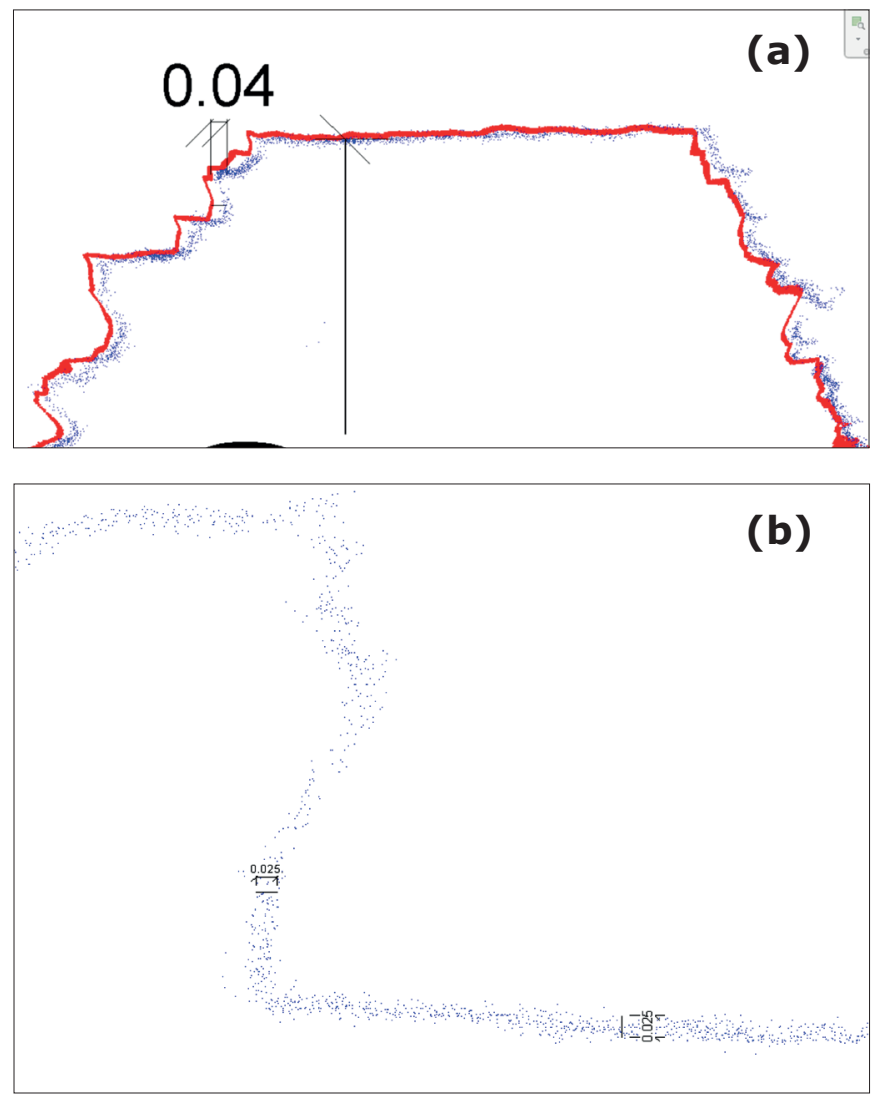

Figura 12. (a) Análisis comparativo de las nubes de puntos. TLS (rojo), MMS (azul). En la cámara 2 se observa un desplazamiento homogéneo de $4 \mathrm{~cm}$. Las distancias se han medido mediante la aplicación CloudCompare. (b) Ruido $(2,5 \mathrm{~cm})$ en la nube de puntos producto de la medición Lidar del MMS.

El análisis de la precisión del sistema MMS respecto de datos de referencia obtenidos por TLS y fotogramétrica SFM se ha realizado mediante el ajuste de las nubes con algoritmos ICP utilizando la aplicación de código abierto CloudCompare para su mejor ajuste.

Como se puede observar el error en ajuste entre las diferentes nubes de puntos es inferior a $2 \mathrm{~cm}$ salvo en la segunda cámara que ha sido de $4 \mathrm{~cm}$ (Fig. 12a). La amplitud y geometría uniforme de la primera cámara hace que la nube de puntos capturada por el escáner láser (rojo) presenta una mejor definición que la nube generada por fotogrametría (verde) y muy similar, aunque con mayor ruido que la nube generada con sistemas MMS (azul) (Fig. 12b). Sin embargo, el complicado pasillo de acceso que conecta ambas salas dificulta la unión y registro de las nubes de puntos TLS, imposibilitando el registro completo. El desplazamiento uniforme de la nube de puntos MMS en la segunda cámara respecto de las nubes TLS y fotogramétricas se debe a la excesiva estrechez del hueco que las comunica que impide un mejor ajuste geométrico entre los registros. Por otro lado, la falta de planeidad de los paramentos impide un ajuste automatizado mayor, no siendo válida la comparación estadística de las distancias "de nube a nube" por no seguir una distribución normal, tal y como apuntan las investigaciones realizadas por Maboudi, Bánhidi y Gerke (2018).

Otro factor a tener en cuenta en la comparación "nube a nube" es la diferencia en la densidad de los registros dependiendo de las zonas donde se realiza la muestra y que fundamentalmente viene condicionada por el ángulo de incidencia del haz láser y la distancia al punto de escaneo (Zogg 2008). Por otro lado, es necesario tener en cuenta que la mayor densidad de puntos no es sinónimo de mayor calidad, pues en el registro con TLS deben existir zonas con amplio solape que no siempre están bien conectadas debido al diferente ángulo de incidencia en la captura.

Tras el análisis geométrico de las diferentes nubes de puntos (MMS, TLS y fotogrametría multi-imagen) se observa que en las zonas de paso estrechas entre las diferentes estancias se producen unas desviaciones mayores, producto del escaso solape. Estas desviaciones se deben a la falta de precisión en la localización de los dispositivos MMS al no existir suficientes planos de referencia o presentar geometrías poco robustas. Por este motivo recomendamos reducir la velocidad en estas zonas y sobre todo acceder de espaldas por disponer de mayor número de referencias en la sala desde la que se accede.

\subsection{Evaluación del rendimiento en cuanto tiempo de captura y procesamiento}

Sin lugar a dudas la principal ventaja de los dispositivos MMS es la facilidad y rapidez con la que se captura el modelo tridimensional objeto de estudio. La velocidad de desplazamiento del operador influye de manera directa en la densidad de la nube de puntos capturada, así como en la calidad geométrica de las zonas de paso. Con objeto de disponer de datos comparativos, se realizaron dos recorridos de ida y vuelta (bucle cerrado) a diferente velocidad. En el primero se empleó un tiempo de $15 \mathrm{~min}$ ( 0,25 horas) obteniendo una nube de 16.718 .676 puntos, en el segundo, más rápido, se tardó 8 min obteniéndose una nube de 6.827 .759 puntos. Otro factor importante en los sistemas MMS es que no necesitan la captura de puntos de control ni apoyo topográfico salvo para la georreferenciación del edificio o yacimiento. Tareas 
estas que consumen mucho tiempo y necesitan bastante especialización para que la precisión sea adecuada al registro.

\subsection{Evaluación de la calidad gráfica de los documentos}

Uno de los aspectos que consideramos fundamentales a la hora de evaluar un dispositivo de captura masiva es el necesario reconocimiento de las características geométricas de los elementos arquitectónicos o arqueológicos sobre la nube de puntos o la posibilidad de generar ortoimágenes de referencia. En este sentido, los factores que más influyen son: la densidad de los puntos capturados, el ruido generado por el dispositivo de medición o la disponibilidad de la textura RGB de los puntos.

El mayor inconveniente del equipo MMS utilizado en la investigación -GeoSLAM Zeb-Revo ${ }^{20}$ - es que la nube resultante no dispone de textura. Si bien el equipo dispone de una cámara gran angular Gopro que graba un video del recorrido, el software de descarga y tratamiento de datos, GeoSLam-HUB, no permite la sincronización de la imagen con la nube de puntos, por lo que solo ha sido posible su visualización monocroma (Fig. 13).

Por otro lado, la menor densidad de puntos registrada impide una adecuada visualización de los elementos constructivos (en nuestro caso mampostería). El dispositivo GeoSlam Zeb Revo ha registrado de forma continua y completa la geometría del tholo, incluso en aquellas zonas donde los otros sistemas no han podido acceder, pero la densidad de puntos obtenida no es suficiente para el reconocimiento de los detalles constructivos que son necesarios para su correcta documentación gráfica (Fig. 14a). En este sentido, los modelos 3D generados por fotogrametría multi-imagen aportan la densidad y textura necesarias para la correcta interpretación y documentación (Fig. 14b).

20 El equipo GeoSLAM ZEB REVO ha sido facilitado por la empresa Geoavance S.L. de Sevilla.

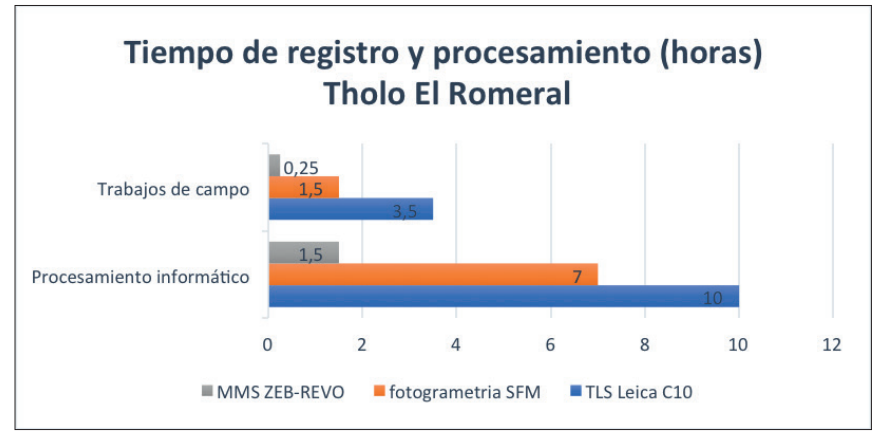

Figura 13. Gráfico comparativo de tiempos (en horas) de captura y procesado entre las diferentes técnicas de registro masivo. Elaboración propia.

\begin{tabular}{|l|l|l|}
\hline & $\begin{array}{l}\text { Trabajo de campo } \\
\text { en campo }\end{array}$ & $\begin{array}{l}\text { Procesamiento } \\
\text { informático }\end{array}$ \\
\hline TLS Leica C10 & 3,5 & 10 \\
\hline Fotogrametría SFM & 1.5 & $7^{(* *)}$ \\
\hline MMS ZEB-REVO & 0,25 & $1,5^{(* *)}$ \\
\hline
\end{tabular}

(**) Procesamiento autónomo.

Tabla 3. Tiempo (en horas) empleado en la captura y procesado de datos.

\subsection{Documentación gráfica del tholo de EI Romeral}

En la actualidad, todos los datos se registran, almacenan, procesan y analizan mediante el uso de herramientas digitales (Previtali y Valente 2019). El registro y gestión de los bienes patrimoniales mediante modelos digitales tridimensionales permite un mejor estudio y conocimiento. La generación de documentos gráficos es cada vez más completa y precisa realizándose reproducciones virtuales que se pueden considerar hiperrealistas. Modelos tridimensionales de nubes de puntos o de mallas texturizadas son gestionados por un amplio abanico de aplicaciones informáticas para producir representaciones 2D o modelos y vistas tridimensionales que mejoran y facilitan su compresión y difusión (Martín

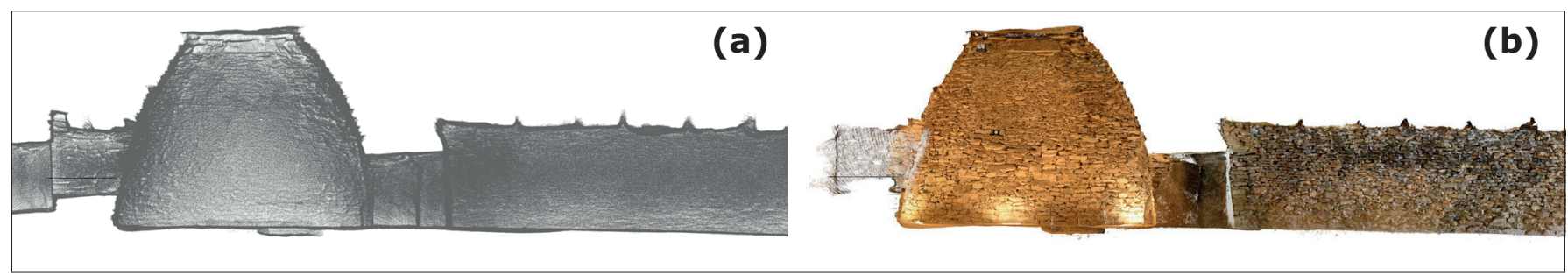

Figura 14. Detalle de nube de puntos realizada por MMS GeoSlam Zeb-Revo (a) y por fotogrametría multi-imagen (b). La falta de textura de la nube MMS impide el registro de los elementos constructivos o las unidades estratigráfica (UUEE). Elaboración propia. 
Talaverano 2014). De igual manera, las tecnologías digitales facilitan el intercambio y la interoperabilidad entre los agentes intervinientes. Llegados a este punto, creemos importante diferenciar entre dos tipos de producciones gráficas: (1) las representaciones tecnológicas, producto de la gestión de estos modelos virtuales, y (2) las representaciones analíticas producto del análisis y documentación gráfica de los valores culturales materiales que son el objeto de estudio.

Entre las primeras cabe destacar los MDS $^{21}$ (Fig. 15), $\mathrm{MDT}^{22}$ (Fig. 16), ortofotografías (Fig. 17) o las

21 MDS: Modelos Digitales de Superficie.

22 MDT: Modelos Digitales del Terreno.

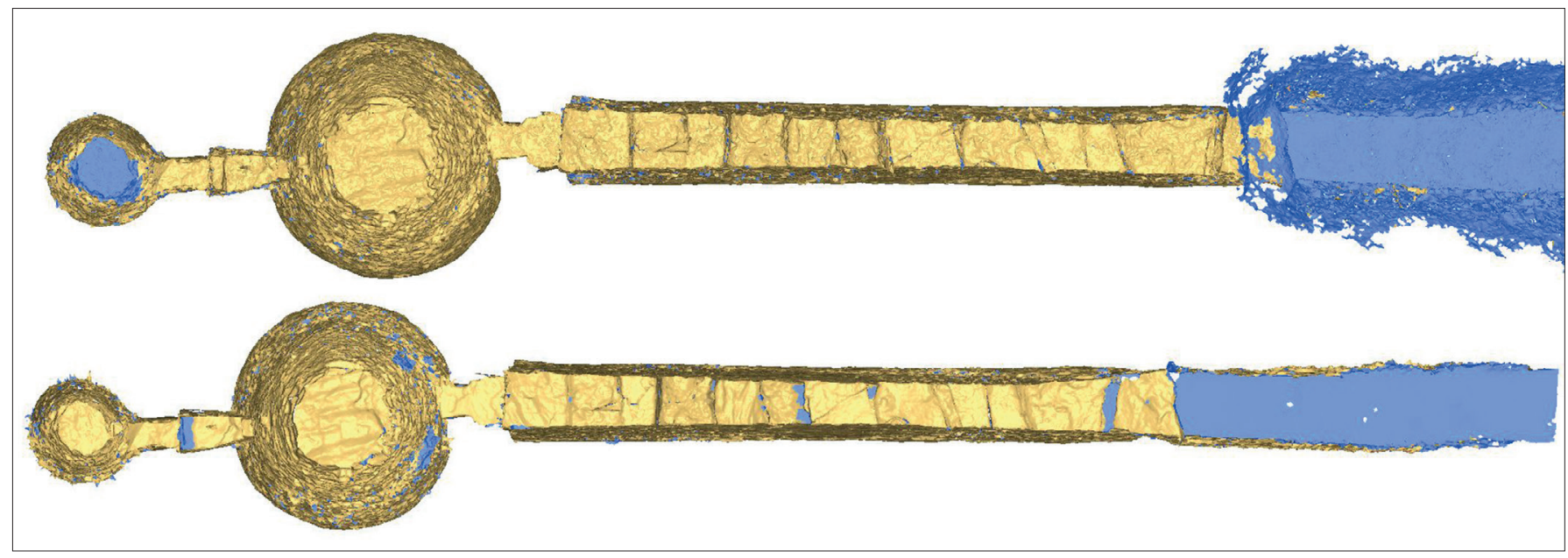

Figura 15. MDS del interior del tholo realizados con dispositivo MMS GeoSlam Zeb Revo (arriba) y escáner laser TLS Leica C-10 (debajo). Elaboración propia.

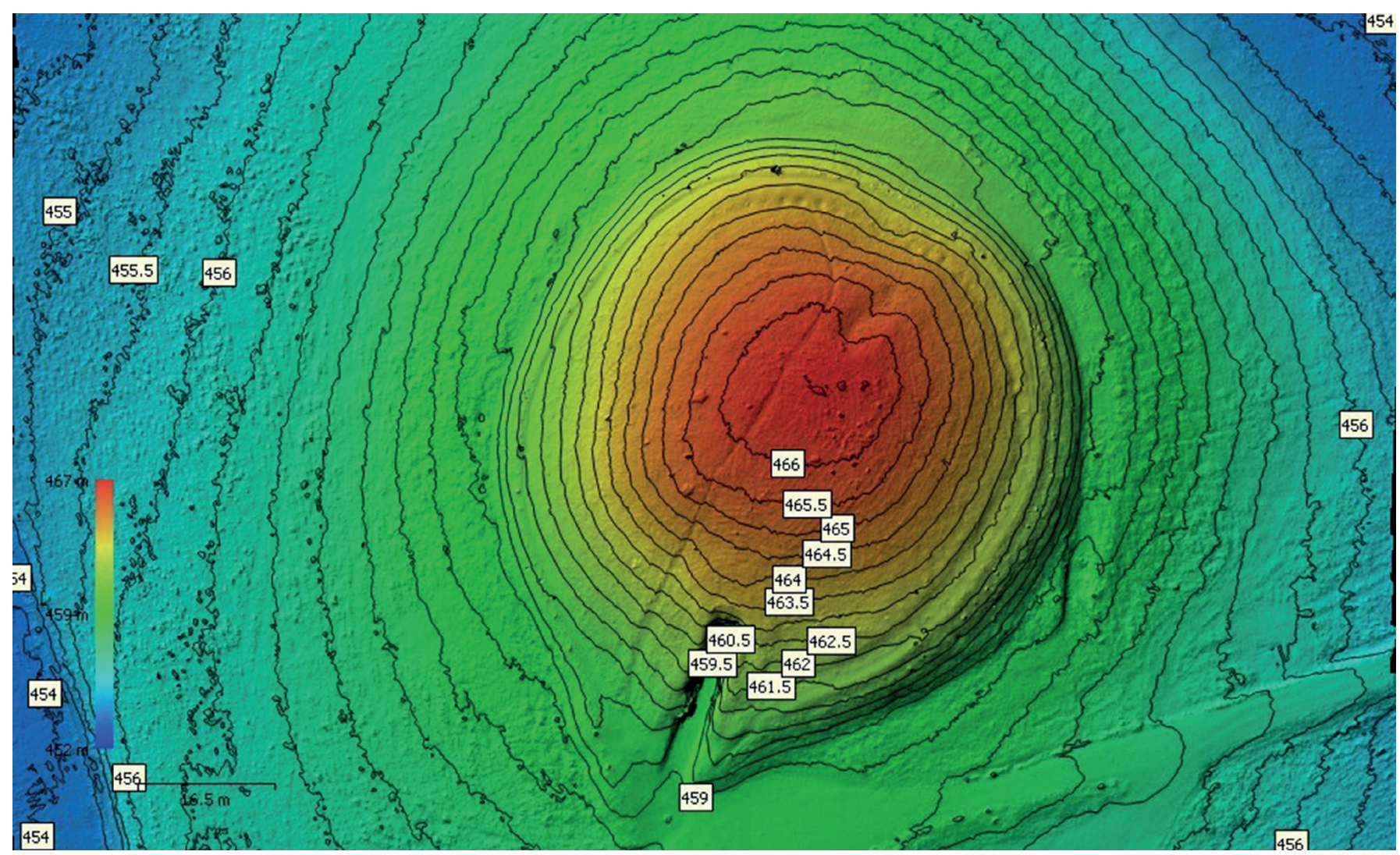

Figura 16. MDT del túmulo de El Romeral con la galería exterior. De acuerdo a las cotas se observa un relleno de 6 m de altura. Elaboración propia. 


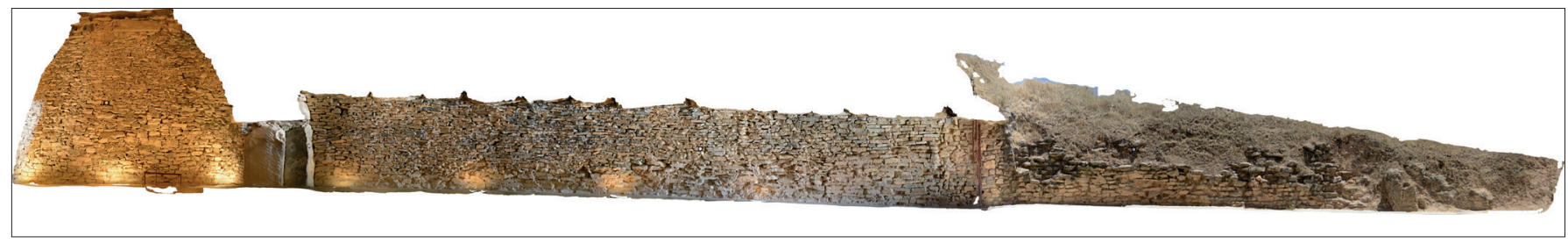

Figura 17. Ortofotografía interior del tholo de El Romeral. La alta resolución de la imagen (GSD de 0.543 mm/pix) permite la documentación precisa de la geometría y los elementos singulares. Elaboración propia.

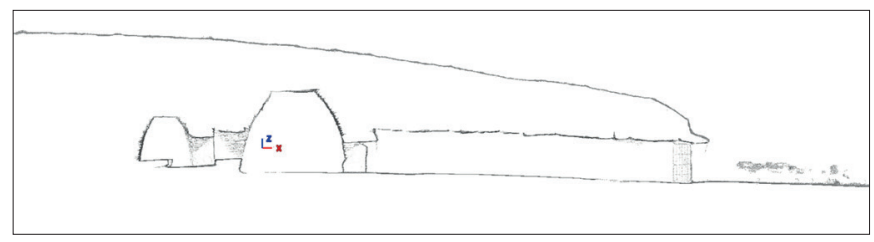

Figura 18. Sección longitudinal del tholo a partir de la nube de puntos MMS en el interior y vuelo fotogramétrico en el exterior. Fuente: los autores.

geometrías generadas por secciones aplicadas al modelo (Fig. 18). Todas ellas constituyen la fuente sobre la que debemos plasmar e informar sobre el análisis arquitectónico o arqueológico realizado (Fig. 19), utilizando el dibujo de línea y las tramas como recurso gráfico habitual (San José Alonso 2018).

La complejidad estructural o histórica del tholo de El Romeral resulta imposible de definir con la sola representación de su planta o sección. Las ortofotografías constituyen una herramienta fundamental para la mejor y más completa documentación de los elementos patrimoniales ya que facilitan el dibujo, permitiendo justificar el análisis realizado o una posterior reinterpretación (Fig. 20).
Por otro lado, entendemos que este dibujo digital debe seguir unos criterios infográficos que permitan un conocimiento riguroso de los elementos patrimoniales sin entrar en representaciones donde se busca más el virtuosismo de quien las realiza. La verdadera finalidad de la documentación gráfica debe ser el adecuado registro de los datos (geometría, elementos constructivos, patologías, contexto arqueológico, etc.) de forma que sean un eficaz medio de análisis y comunicación de los valores culturales que pretendemos preservar (Martín Talverano et al. 2018).

\section{DISCUSIÓN}

Los sistemas MMS se han convertido en una importante herramienta para la adquisición de datos geoespaciales ya que permiten el registro completo, continuo y rápido de la geometría de los elementos estructurales que componen los bienes patrimoniales, incluso en aquellas zonas que, por su escasa dimensión, no son accesibles para los TLS o la captura fotográfica.

El sistema de mapeo móvil simultáneo GeoSlam Zeb-Revo utilizado en nuestra investigación nos ha

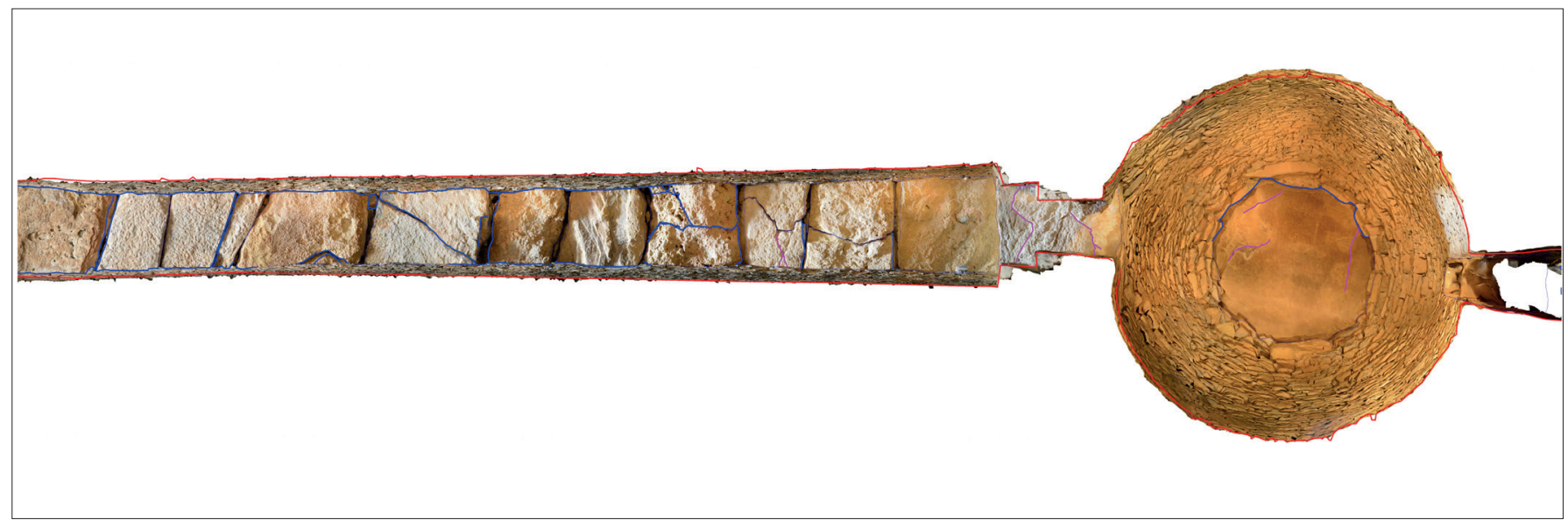

Figura 19. Análisis y dibujo de los ortostatos de techo en corredor y cámara con indicación de las grietas y fisuras a partir de ortofotografía escalada. Elaboración propia. 


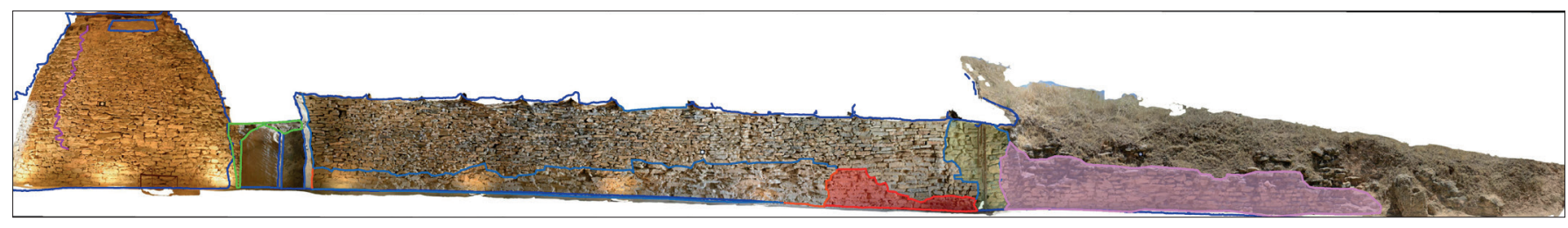

Figura 20. Análisis tipológico de la geometría y materiales en el alzado Este del interior del tholo de El Romeral. Elaboración propia.

permitido un rápido y completo registro tridimensional del tholo de El Romeral mediante dos recorridos cerrados, uno rápido de $8 \mathrm{~min}$ y otro más lento de $15 \mathrm{~min}$. En ambos casos, tal y como hemos recogido en la figura 21, las nubes de puntos generadas disponen de una calidad geométrica similar al de otros sistemas de registro, siendo suficiente para obtener la geometría general de las estructuras (planos de planta o secciones). Sin embargo, la escasa densidad de las nubes de puntos unida a la falta de textura o el ruido que estos dispositivos generan, impiden el reconocimiento de los elementos singulares que son necesarios para su completa documentación, como puede ser la lectura paramental de las unidades estratigráficas para la realización del análisis arqueológico.

La falta de disponibilidad en España nos ha impedido testear el equipo GeoSlam Zeb-CAM que según la casa comercial permite la captura de video simultánea a desplazamiento y la aplicación de color a los puntos de la nube. En cualquier caso, de acuerdo a nuestra experiencia en la gestión de nubes de puntos con textu$\mathrm{ra}$, esto no resuelve el problema ya que la escasa densidad de la nube impide la identificación de los elementos constructivos siendo necesaria la aplicación de la textura directamente sobre la malla para que los resultados sean óptimos.

Los modelos digitales generados con el equipo TLS muestran nubes de puntos poco homogéneas debido a la compleja geometría y reducido espacio de las estancias del tholo, obligando a posicionar el escáner en múltiples lugares con zonas de solape. Por el mismo motivo, las imágenes capturadas desde la posición del escáner producen texturas de mala calidad debido la falta de perpendicularidad respecto de los paramentos.

Según los resultados mostrados en este trabajo, los modelos digitales obtenidos por fotogrametría multiimagen constituyen el soporte más adecuado para la obtención de la documentación gráfica que es necesaria para plasmar los resultados del análisis arquitectónico y

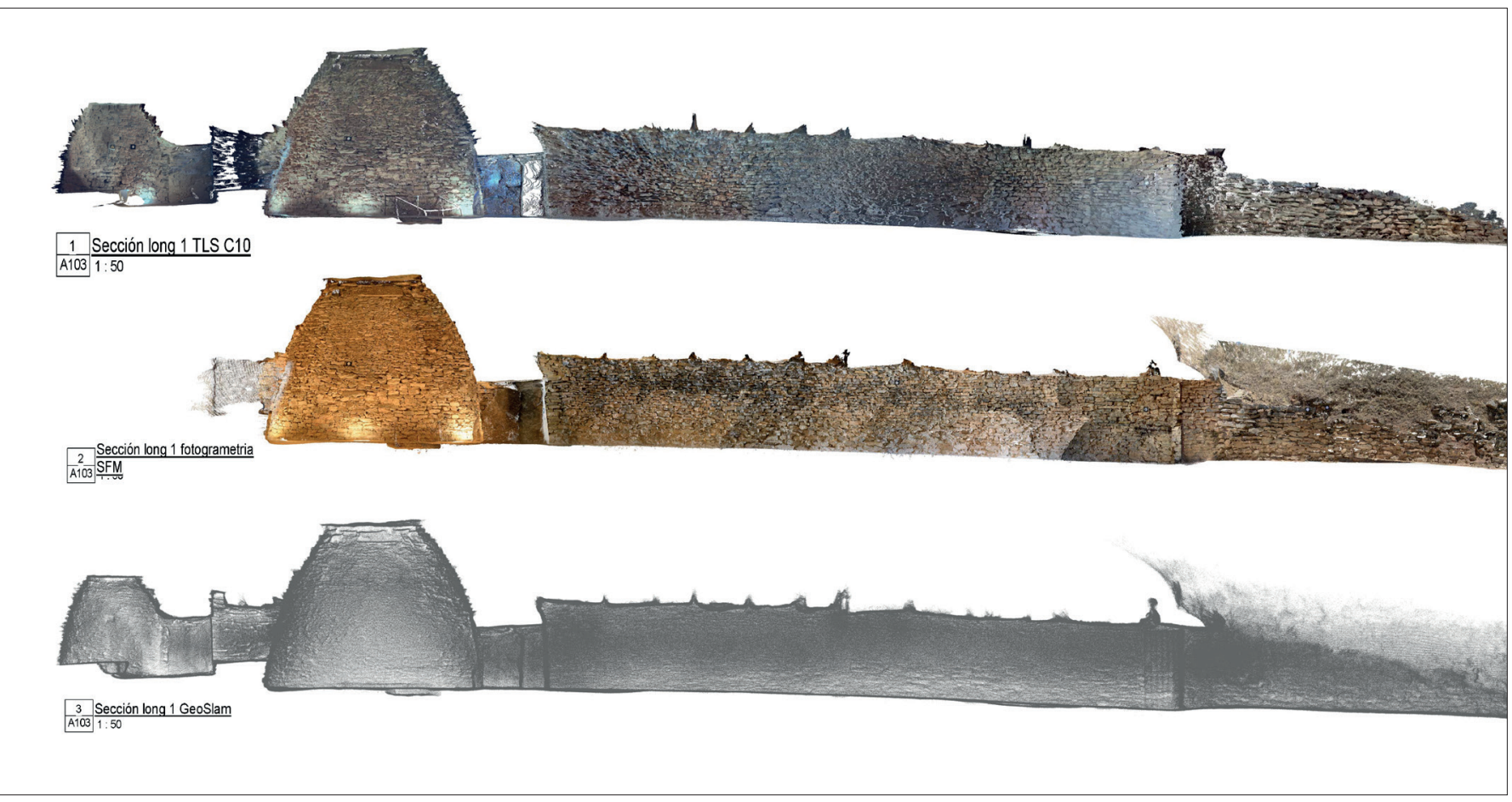

Figura 21. Registro gráfico de los tres sistemas de captura masiva. TLS, fotogrametría SFM, sistema MMS. Elaboración propia. 
arqueológico. La captura rápida y precisa de las imágenes desde múltiples posiciones permite un registro más eficaz de las formas y de la textura. La capacidad que presentan los programas de SFM de orientar correctamente y de forma automática grandes conjuntos de imágenes (Remondino et al. 2017), unida a la calidad métrica de los resultados, hacen que la fotogrametría multi-imagen se presente como una importante alternativa acorde a las necesidades actuales de documentación del patrimonio.

En cuanto al coste se refiere, la fotogrametría de SFM constituye la opción más económica, ya que el equipo necesario se limita a una cámara digital, un equipo topográfico y un software de procesamiento SFM comercial y libre.

\section{CONCLUSIONES}

El análisis cuantitativo y cualitativo de las nubes de puntos generadas con MMS se ha realizado a partir de la comparación con las nubes de puntos generadas mediante escáner láser 3D y las elaboradas mediante fotogrametría multi-imagen. Estas nubes aportan mayor calidad gráfica que las realizadas por MMS pero requieren una mayor especialización y tiempo tanto en los trabajos de campo como en el procesamiento.

El modelo 3D resultante de nuestra investigación aporta una geometría completa del tholo de El Romeral incluso en aquellas zonas estrechas que no han podido ser adecuadamente registradas por los otros sistemas. La escasa densidad de la nube de puntos generada por los dispositivos MMS impide el registro detallado de los elementos constructivos que son necesarios para el completo análisis del tholo de El Romeral.

En zonas de pasos estrechos observamos una disminución de la precisión en el ajuste geométrico de las nubes de puntos. La falta de medidas de referencia o con geometrías más robustas impide una correcta localización del equipo. En este caso y con objeto de mejorar la localización del equipo MMS proponemos que el acceso a las diferentes estancias debe realizarse de espaldas tomando como referencia los datos ya registrados en la estancia desde la que se accede.

No obstante, es necesario seguir experimentando en los procesos de toma de datos e intercambio de información, mejorando la calidad gráfica de los modelos y facilitando la interoperabilidad por parte de otros investigadores y profesionales a través de plataformas de comunicación abiertas. Esto requiere un esfuerzo por parte de todos en una actualización constante de las aplicaciones y técnicas de registro, así como en la fijación de unos estándares en la documentación que es necesaria para este tipo de productos. En este sentido, consideramos importante que en futuras investigaciones, para este tipo de análisis, se empleen equipos que combinan todas las tecnologías utilizadas (escáner láser, IMU, brújulas, GNSS y cámaras HDR) como el RTC360 de Leica o la tecnología blue workflow ${ }^{\circledR}$ de Z+F (Zoler+Fröhlich).

\section{AGRADECIMIENTOS}

Agradecemos la colaboración y ayuda prestada por Bartolomé Ruiz González, director del Conjunto Arqueológico Dólmenes de Antequera. La documentación suministrada y el entusiasmo en sus explicaciones nos sirvieron de gran ayuda para comprender mejor la importancia de estas construcciones y reafirmarnos en la necesidad de este tipo de trabajos de documentación.

Agradecemos la colaboración de la empresa Geoavance S.L. de Sevilla y más en concreto a su gerente Javier Ramos por habernos facilitado el equipo GeoSlam Zeb Revo y ayudado en el procesamiento de las nubes de puntos capturadas por este equipo.

\section{BIBLIOGRAFÍA}

Barrera Vera, J.A. 2006: Aplicación de tecnologías innovadoras en la documentación geométrica del Patrimonio Arquitectónico y Arqueológico. Tesis doctoral. Universidad de Sevilla. https://idus.us.es/xmlui/handle/11441/15843

Barrera Vera, J. A. y Benavides Lopez, J. A. 2018: "Handheld mobile mapping applied to historical urban areas", Disegnarecon, 11, pp. 1-14. http:// disegnarecon.univaq.it/ojs/index.php/disegnarecon/article/view/489

Benavides López, J. A. 2017: Nuevas tecnologías en la documentación del patrimonio: La alcazaba de Guadix-El castillo de Pínar. Tesis doctoral. Universidad de Granada. http://hdl.handle.net/10481/47477

Biosca, J. M., Navarro, S. y Lerma, J. L. 2009: "Estudios previos de fotogrametría en las bóvedas barroca y gótica del presbierio de la Catedral de Valencia”, en C. Pérez García (coord.), Los ángeles músicos de la Catedral de Valencia: estudios previos, pp. 305-312. Generalitat Valenciana, Valencia. Recuperado de: http://jllerma.webs.upv.es/pap021.pdf

Bosse, M., Zlot, R. y Flick, P. 2012: "Zebedee: Design of a spring-mounted 3d range sensor with application to mobile mapping", IEEE Transactions on Robotics, 28 (5), pp. 1104-1119. https://doi.org/10.1109/tro.2012.2200990

Chiabrando, F., D’Andria, F., Sammartano, G. y Spanò, A. 2018: "UAV photogrammetry for archaeological site survey. 3D models at the Hierapolis in Phrygia (Turkey)", Virtual Archaeology Review, 9 (18), p. 28. https://doi. org/10.4995/var.2018.5958

Filgueira, A., Arias, P., Bueno, M. y Lagüela, S. 2016: "Novel inspection system, backpack-based, for 3D modelling of indoor scenes", en Proceedings of the International Conference on Indoor positioning and 
Navigation, pp. 4-7., Alcalá de Henares. http://www3.uah.es/ipin2016/usb/app/ descargas/194_WIP.pdf

García-Gómez, I., de Gorostiza, M. F. y Moraza, A. M. 2011: "Láser escáner y nubes de puntos. Un horizonte aplicado al análisis arqueológico de edificios". Arqueología de la Arquitectura, 8, pp. 25-44. https://doi. org/10.3989/arqarqt.2011.10019

Gonizzi Barsanti, Sara \& Remondino, Fabio \& Visintini, Domenico. (2012). Photogrammetry and laser scanning for archaeological site 3D modeling Some critical issues. CEUR Workshop Proceedings. 948. B1-B10. https:// www.researchgate.net/publication/286135235_Photogrammetry_and_laser_ scanning_for_archaeological_site_3D_modeling___Some_critical_issues

Karam, S., Vosselman, G., Peter, M., Hosseinyalamdary, S. y Lehtola, V. 2019: "Design, Calibration, and Evaluation of a Backpack Indoor Mobile Mapping System". Remote sensing, 11 (8), p. 905. https://doi.org/10.3390/ rs11080905

Kohlbrecher, S., Meyer, J., Graber, T., Petersen, K., Klingauf, U. y von Stryk, O. 2013: "Hector open source modules for autonomous mapping and navigation with rescue robots", en Robot Soccer World Cup, pp. 624-631. Springer, Berlin, Heidelberg. https://doi.org/10.1007/978-3-662-44468-9_58

Lehtola, V. V., Kaartinen, H., Nüchter, A., Kaijaluoto, R., Kukko, A., Litkey, P., Honkavaara, E., Rosnell, T., Vaaja, M. T. y Virtanen, J. P. 2017: “Comparison of the selected state-of-the-art 3D indoor scanning and point cloud generation methods". Remote sensing, 9, p. 796. https://doi.org/10.3390/ rs9080796

Lerma, J. L., Navarro, S., Cabrelles, M., Seguí, A. E., Haddad, N. y Akasheh, T. 2011. "Integration of laser scanning and imagery for photorealistic 3D architectural documentation", en Laser scanning, theory and applications, pp. 413-430. https://doi.org/10.5772/14534

Lynen, S., Sattler, T., Bosse, M., Hesch, J. A., Pollefeys, M. y Siegwart, R. 2015: "Get Out of My Lab: Large-scale, Real-Time Visual-Inertial Localization". Robotics: Science and Systems, 1. https://doi.org/10.15607/ rss.2015.xi.037

Maboudi, M., Bánhidi, D. y Gerke, M. 2017: "Evaluation of indoor mobile mapping systems", en Proceedings of the GFaI Workshop 3D North East, pp. 125-134. Berlín. https://www.researchgate.net/publication/321709273 Evaluation_of_indoor_mobile_mapping_systems

Maboudi, M., Bánhidi, D. y Gerke, M. 2018: "Investigation of geometric performance of an indoor mobile mapping system", ISPRS Annals of the Photogrammetry, Remote Sensing and Spatial Information Sciences, 42, pp. 637-642. https://doi.org/10.5194/isprs-archives-XLII-2-637-2018

Martín Talaverano, R. 2014: "Documentación gráfica de edificios históricos: principios, aplicaciones y perspectivas". Arqueología de la Arquitectura, 11, pp. 1-26. http://dx.doi.org/10.3989/arq.arqt.2014.014

Martín Talaverano, R., Cámara Muñoz, L. y Murillo Fragero, J. I. 2018: "Análisis integrado de construcciones históricas: secuencia estratigráfica y diagnóstico patológico. Aplicación en la iglesia de Santa Clara (Córdoba)". Arqueología de la Arquitectura, 15, e067. https://doi.org/10.3989/ arq.arqt.2018.001

Martínez Rubio, J., Fernández Martín, J. J. y San José Alonso, J. I. 2018: "Implementation of 3D scanner and digital photogrammetry in the documentation process of la Merced Church, Panama”. EGA Expresión
Gráfica Arquitectónica, 23 (32), pp. 208-219. https://doi.org/10.4995/ ega.2018.9811

Moon D., Kwon S., Seo J. y Shin J. 2019: “Comparison and utilization of point cloud generated from photogrammetry and laser scanning: 3D world model for smart heavy equipment planning". Automation in Construction, 98, pp. 322-331. https://doi.org/10.1016/j.autcon.2018.07.020

Nocerino, E., Menna, F., Remondino, F., Toschi, I. y Rodríguez-Gonzálvez, P. 2017: "Investigation of indoor and outdoor performance of two portable mobile mapping systems", en Videometrics, Range Imaging, and Applications XIV (10332), p. 103320I. International Society for Optics and Photonics. https://doi.org/10.1117/12.2270761

Previtali, M. y Valente, R. 2019. Archaeological documentation and data sharing: digital surveying and open data approach applied to archaeological fieldworks. Virtual Archaeology Review, 10 (20), pp. 17-27. https://doi. org/10.4995/var.2019.10377

Remondino, F., Nocerino, E., Toschi, I. y Menna, F. 2017: "A critical review of automated photogrammetric processing of large datasets". International Archives of the Photogrammetry, Remote Sensing \& Spatial Information Sciences, 42. https://doi.org/10.5194/isprs-archives-XLII-2-W5-591-2017

Rodríguez-Navarro, P. 2012: "La Fotogrametría Digital Automatizada frente a los sistemas basados en sensores 3D activos", EGA Expresión Gráfica Arquitectónica, (17), pp. 100-111. https://doi.org/10.4995/ega.2012.1408

Ruiz Gonzalez, B. 2011: El Conjunto Arqueológico Dolmenes de Antequera: Definición, programación e institucionalización: Documento de avance del Plan Director. Tomo I. Consejería de Cultura. Junta de Andalucia. https://issuu.com/dolmenesdeantequera.ccul/docs/09_conjunto_arqueolo_gico_dolmenes_f3d043e77e7b4d

San José Alonso, J. I. 2018: "Levantamiento, tecnología y documentación de la arquitectura", EGA Expresión Gráfica Arquitectónica, 23 (34), pp. $240-$ 251. https://doi.org/10.4995/ega.2018.10937

Sirmacek, B., Shen, Y., Lindenbergh, R., Zlatanova, S. y Diakite, A. 2016: "Comparison of ZEB1 and Leica C10 indoor laser scanning point clouds". ISPRS Annals of the Photogrammetry, Remote Sensing and Spatial Information Sciences, pp. 143-149. https://doi.org/10.5194/isprsannalsIII-1-143-2016

Smith, R., Self, M. y Cheeseman, P. 1990: "Estimating uncertain spatial relationships in robotics", en Autonomous robot vehicles, pp. 167-193. Springer,.

Szeliski, R. 2010: Computer vision: algorithms and applications. Springer Science \& Business Media,. http://szeliski.org/Book/drafts/SzeliskiBook_20100903_ draft.pdf

Tucci, G., Visintini, D., Bonora, V. y Parisi, E. 2018: "Examination of indoor mobile mapping systems in a diversified internal/external test field". $A p$ plied Sciences, 8 (3), p. 401. https://doi.org/10.3390/app8030401

Zhang, J. y Singh, S. 2014: "LOAM: Lidar odometry and mapping in realtime", en Proceedings of the Robotics: Science and Systems Conference, pp. 109-111. Berkeley, CA, USA https://www.ri.cmu.edu/pub_files/2014/7/ Ji_LidarMapping_RSS2014_v8.pdf

Zogg, H. M. 2008: Investigations of high precision terrestrial laser scanning with emphasis on the development of a robust close-range $3 D$-laser scanning system. Doctoral dissertation. ETH Zurich. 